\title{
A Novel Dual Signaling Axis for NSP 5a3a induced apoptosis in Head and Neck Carcinoma
}

\author{
Luca D'Agostino ${ }^{1,2}$ and Antonio Giordano ${ }^{1,2}$ \\ ${ }^{1}$ Sbarro Institute for Cancer Research and Molecular Medicine \& Department of Biology, College of Science and Technology \\ Temple University, 1900 North 12th street room 431, Philadelphia PA 19122, USA \\ 2 Department of Human Pathology and Oncology, University of Siena, Siena, Italy \\ Correspondence to: Luca D'Agostino, email: lucadag@temple.edu \\ Keywords: NSP 5a3a, Head and Neck Carcinoma, TNFR-1 signaling pathway
}

Received: August 21, 2011,

Accepted: December 8, 2011,

Published: December 14, 2011

Copyright: @ D'Agostino et al. This is an open-access article distributed under the terms of the Creative Commons Attribution License, which permits unrestricted use, distribution, and reproduction in any medium, provided the original author and source are credited.

ABSTRACT:

NSP $5 a 3 a$ is a novel structural protein found to be over-expressed in certain cancer
cell lines in-vitro such as Hela, Saos-2, and MCF-7 while barely detectable levels
in normal body tissues except for Testis. This particular isoform has been known
to interact with cyto- nuclear proteins B23, known to be involved in multi-faceted
cellular processes such as cell division, apoptosis, ribosome biogenesis, and rRNA
processing, as well as with hnRNP-L, known to be involved with RNA metabolism
and rRNA processing. A previous preliminary investigation of NSP 5 a3a as a potential
target in Head and Neck Carcinoma revealed a novel p73 dependent mechanism
through which NSP 5 a3a induced apoptosis in Head and Neck cell lines when over-
expressed in-vitro. Our present investigation further elucidated a novel dual axis
signaling point by which NSP 5a3a induces apoptosis in Head and Neck cell line
HN30 through p73-DAXX and TRAF2-TRADD. Interestingly, this novel mechanism
appears independent of canonical caspases involved in the intrinsic mitochondrial
pathway as well as those in the death receptor pathway thru TRAF2 and TRADD.

\section{INTRODUCTION}

Head and Neck squamous cell carcinomas (HNSSCs) being the fifth or sixth most common form of cancer worldwide depending on sources [8-9] has shown an increasing incidence with greater than 40,000 cases diagnosed each year in the United States and approximately 500,000 globally [10] though in the last forty years there has been no significant improvement in overall mortality and survival from this aggressive form of cancer [11-12]. Typically, the 5-year survival rates have been around $50 \%$ in the past twenty years, due to the lack of positive prognosis and reliable tumor markers for this pathological and biological diverse type of cancer hence its diverse clinical profiles and treatment [13]. Usually, general treatment involves surgery or combination of radiation and chemotherapy. Most patients will suffer from recurrences, whether locally or regionally, being from primary sites or becoming metastatic and spreading throughout the lymph nodes even still after surgery and or in combination with chemotherapy, will experience within two years and with significant decrease in overall survival by a half [14-16]. HNSSC can originate from various parts of the upper digestive/oral tract being and including larynx, oral and nasal cavities, pharynx, and esophagus [17]. HNSSC's can occur from common carcinogens found in tobacco products as well as in combination or not with of alcohol consumption [18-19] though there are cases of HNSSC where the cause is viral being from HPV (Human Papilloma virus) in about 30\% of cases [20]. Thus, given the general poor prognosis and high risk of cancerous recurrences even from secondary primary tumor sites, there is push through development of novel biologic therapies including gene therapy to promote better tumor growth control or regression with higher survival rates. Such strategies have included p53 based adenoviral gene therapy [21] as well as Fas ligand adenoviral gene therapy [22].

Apoptosis also known as programmed cell death or cell suicide is a critical complex intrinsic cellular process involved in normal tissue homeostasis and development. This highly evolutionary conserved process occurs not 
only in normal cellular and tissue physiology but has been implicated in various pathological diseases such as cancer, autoimmune diseases, and dementia [23-29]. Typically, apoptosis is characterized by distinct morphological and biochemical features which include shrinkage of the cell followed by cleavage of cytoskeletal components such as actin and lamins, nuclear condensation and DNA fragmentation, ending with membrane blebbing and apoptotic bodies in late stage apoptosis [30-32].

Apoptosis can be initiated either through extrinsic or intrinsic signaling pathways which involve the death receptor ligand complex and mitochondria, respectively. Activation of the extrinsic pathway usually involves the tumor necrosis family (TNF) receptor superfamily including TNFR1, TRAIL-R1, TRAIL-R2, or CD95 (APO-1-Fas) involving its trimeric membrane receptor formation upon contact with its appropriate extracellular ligand and recruitment of adaptor molecules [33]. In the case of CD95 and TRAIL induced apoptosis, there is recruitment of FADD adaptor molecule and caspase 8 which becomes activated and cleaves downstream effector caspases such as caspase 3,6, and 7 depending on the cell type or there is involvement of the mitochondria in a positive feedback loop thru cleavage of Bid [34-35]. While, in the case of TNF-R1 induced apoptosis, there is recruitment of adaptor molecules TRADD with FADD, or with RAIDD, which can lead to caspase 8 activation followed by subsequent cleavage and activation of downstream effector caspases such as caspase 3, 6, and 7 or caspase 2 activation converging on the same activation of effector caspases as mentioned before [36-38]. The intrinsic pathway also known as the mitochondrial pathway, involves the release of apoptotic factors from the mitochondrial intermembrane space such as apoptosis inducing factor (AIF), cytochrome c, or Smac/DIABLO. The release of cytochrome into the cytoplasm allows the formation of an apoptosome complex formed by cytochrome c, Apaf-1, and caspase 9 which subsequently activates caspase 3 [39-41]. Whereas SMAC/DIABLO help enhance caspase activation by inhibiting antiapoptotic factors such as IAPs (inhibitors of apoptosis proteins) while AIF causes changes in DNA condensation [42-44]. Both pathways can be interconnected at different points such as in the case of caspase 8 , where it can initiate the mitochondrial pathway by by cleavage of BID, leading to $\mathrm{BAX} / \mathrm{BAK}$ dependent cytochrome $\mathrm{c}$ release from the mitochondria and apoptosome formation resulting in caspase 9 activation [44-45]. Then, subsequent caspase activation of caspases 3 and 7 can occur with further activation of caspases of 2 and 6 . Though, it has been noted that when particular caspases are impaired functionally or not expressed, other caspases along the cascade can continue the processing to downstream effectors [46].

TRAF2 (tumor necrosis factor receptor associated factor) is a member of a highly evolutionary conserved family of adaptor proteins (TRAFs) which have been found to participate in a multitude of biological processes such as: immunity, embryonic development, stress responses and bone metabolism being mediated thru TRAFs signaling leading to cell proliferation, differentiation, and apoptosis [47]. The biological effects caused by the TRAF signaling, is possible through the activation of NF$\mathrm{kB}$ and AP-1 pathways which lead usually to cell survival and apoptosis, respectively [48-50] though there is also evidence of NF-kB and AP-1 pathways being involved in apoptosis and cell proliferation as well, respectively [51-52]. Upon TNFR1 stimulation, depending on cellular microenvironment and stimuli, TRAF2 can be recruited to form a complex with another adaptor protein known as TRADD which associates with the death domain regions of the trimerized TNFR1 through its own intracellular death domains, also being able to recruit other signaling molecules such as FADD and RIP [53-54]. Depending on which signaling complex is released from TNFR1, there can be downstream activation of NF-kB through TRAF2/ RIP complex resulting in pro-survival genes or even AP-1 activation by TRAF2 through upstream activation of ASK1/JNK leading to apoptosis. Should the levels of TRAF2 be deficient in the cytoplasm or absent along with limited accessibility of anti-apoptotic proteins c-IAP and FLICE, then the TRADD/FADD along with caspase 8 can initiate downstream caspase activation with subsequent apoptosis [54-57].

P73, a transcription factor belonging to the p53 family, is known to have shared and distinct functions with other p53 members, though all involved in regulating the fate of cells between cell growth and apoptosis during normal development, differentiation, and cellular stress [58-60], it has been shown to be specifically involved in biological processes such as neurogenesis, immunity and negative regulation of p53 activity [6163]. P73 in common with other p53 members can bind and transcriptionally differently activate p53 target genes which can be involved in apoptosis and cell cycle arrest. Depending on the particular p53 member that is expressed and which isoforms in that particular tissue or cells will determine the overall fate [64-65]. P73 can exist in multiple isoforms being either amino-terminal or carboxy-terminal splice variants of the full length Tap73 isoform in which the full length and carboxy-terminal truncated isoforms have been associated with pro-apoptotic functions along with cell growth arrest and tumor suppression while the truncated amino terminal isoforms $\Delta \mathrm{Np} 73$ have been associated with primarily anti-apoptotic functions as well as having negative regulatory activities on p53 and TAp73 isoforms [65-67]. Different modes of action have been attributed to $\mathrm{p} 73$ in the induction of apoptosis, which have primarily been linked to either DNA damage or cytosolic stress. Once activated and depending on the stimuli, p73 particularly TAp73 can induce apoptosis through ER stress via the transactivation of Scotin, or can activate the mitochondrial intrinsic pathway through transactivation 
of PUMA with subsequent translocation and activation of BAX, as well as activate the death receptor pathway [68]. Interestingly, in regards to the activation of the death receptor pathway, p73 has been shown to have transcriptional activity in the sensitization of cells to apoptosis through a Fas mediated caspase dependent mechanism [69] as well as being involved in ASK1/JNK signaling leading to apoptosis [70-71], by which this pathway has been linked to Fas signaling through DAXX which has been shown to interact with p73 [72].

NSP 5a3a along with three other splice variants isoforms: NSP 5b3a, 5a3b, and 5b3b were identified having slight homology to DNA repair Sbc proteins and SMC (structural maintenance chromosome) proteins while higher homology to Specc1 and Cytospin A renal carcinoma antigen was observed whose functions are functions are yet to characterized. These NSP isoforms having features of Spectrin like repeat proteins suggests they may be novel members of this superfamily of proteins which can be involved in a plethora of cellular activities ranging from intracellular structural integrity in the cytoskeleton and matrix in both the cytoplasm and nucleus [73-74] to intracellular trafficking [75], maintenance of organelle function, integrity [75], and

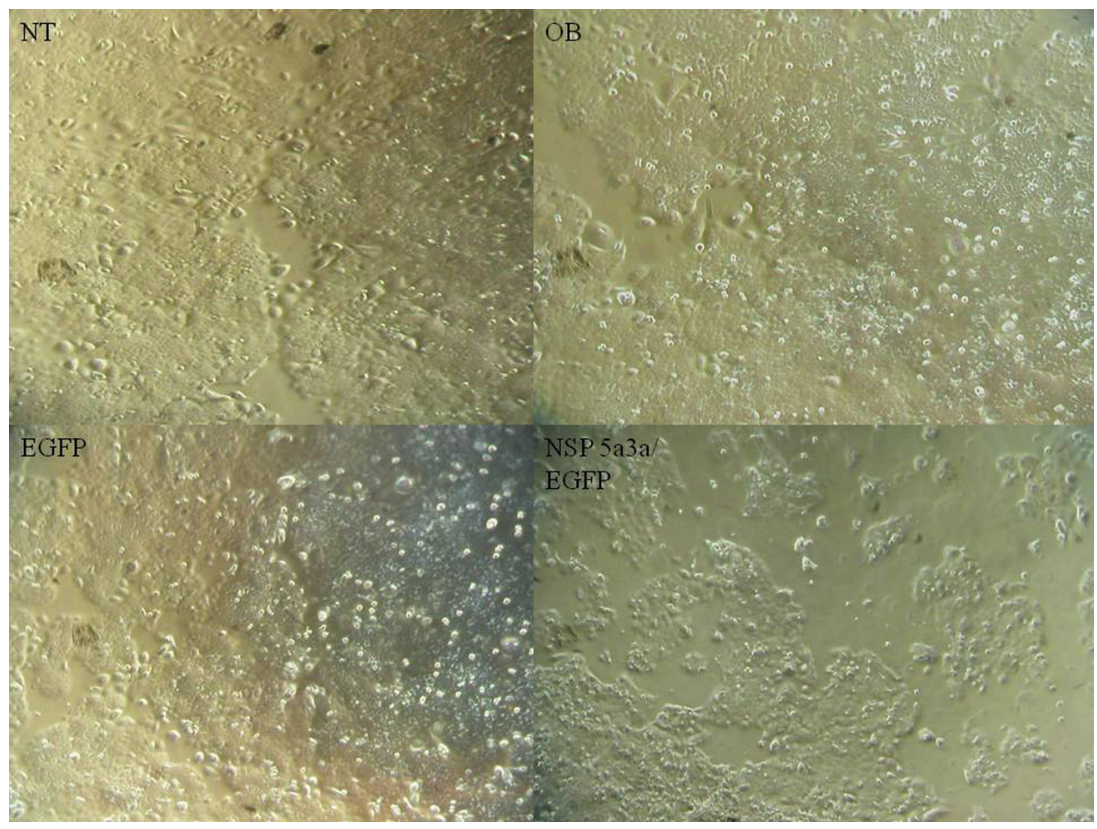

Figure 1: Morphological observation of HN30 cells 3 days post-transfection. NT: non-treated, OB: only buffer, EGFP: only pcDNA3.1/CT-GFP vector, NSP 5a3a/EGFP: pcDNA 3.1/CT-GFP and pcDNA 3.0 NSP 5a3a.

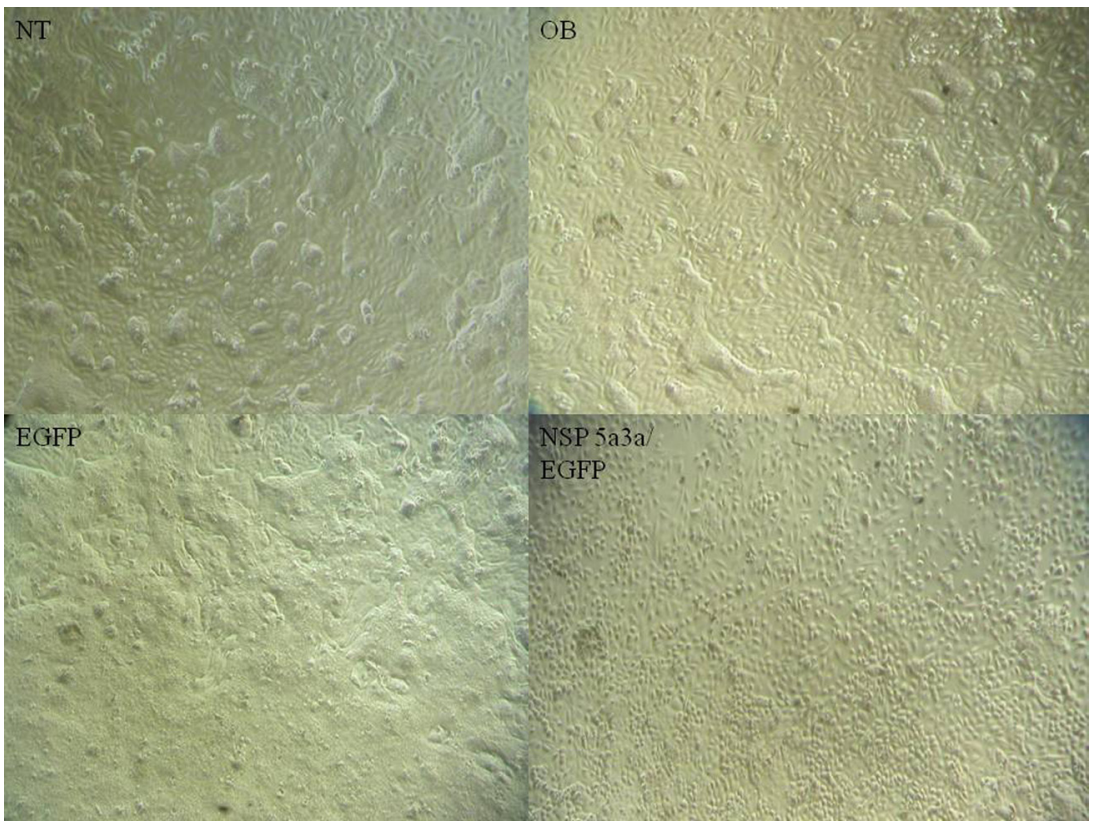

Figure 2: Morphological observation of MCF-12a cells 3 days post-transfection. NT: non-treated, OB: only buffer, EGFP: only pcDNA3.1/CT-GFP vector, NSP 5a3a/EGFP: pcDNA 3.1/CT-GFP and pcDNA 3.0 NSP 5a3a. 
endocytosis [76], nuclear reassembly in Telophase [77], to being scaffolding proteins with other cytoskeletal proteins involved in signal transduction pathways [78].

The NSP 5a3a isoform was found to be expressed differently in-vitro, while moderate in some other showed higher levels of expression such as: HT-29, MCF-7, Hela, HN30, Saos-2, CEM, and H23 [1]. NSP 5a3a was shown to interact with B23, a multi-functional nucleolar in Hela cells both in cycling and in dividing cells. This suggested a likely involvement of NSP 5a4a during cell division with B23 and as well as other B23 functions pathways [2]. Subsequently, we showed and verified that NSP 5a3a, B23, and hnRNP-L (heterogeneous ribonuclearprotein) interacted with each other in both MCF-7 (breast adenocarcinoma) and MCF-12A (normal breast) cell lines though in a both compartment and cell-type specific manner [4]. This novel interaction between NSP 5a3a with B23 and hnRNP-L raised the possibility of implicating NSP 5a3a in RNA metabolism and RNA processing both of which B23 and hnRNP-L have been confirmed to have important roles involving RNA processing and regulation [5-6].

Our previous study had demonstrated that overexpression of NSP 5a3a induced significant apoptosis in head and neck carcinoma cell lines in particular in HN30 being p53 independent yet involving a novel p73 dependent mechanism. Thus, we had proposed NSP 5a3a as a potential therapeutic target to be investigated further, since it could have potential in a site-directed manner to treat cancer types that behave through a similar p73 dependent mechanism as found in the head and neck carcinoma cell lines we investigated previously [7]. We further elucidated this novel p73 mechanism thru NSP $5 \mathrm{a} 3 \mathrm{a}$ showing the involvement of TNF associated proteins TRAF2 and TRADD along with the TGF-beta/FAS associated apoptotic protein DAXX.

\section{RESULTS}

\section{Morphological and Immunofluorescence analysis of HN30 over-expressing NSP 5a3a}

Asynchronous HN30 cells were transfected with pcDNA3.0 NSP 5a3a vector along with controls after which images of the cells were taken three days post-transfection and prepared for immune-staining to assess the effect of NSP 5a3a over-expression on protein distribution of NSP 5a3a, p73, TRAF2, and TRADD. Images of HN30 cells three days post-transfection revealed that treated cells with NSP 5a3a seemed more stressed with appearance of floating cells and fewer attached cells to the plate surface indicative of possible apoptosis (Fig. 1). Controls were seemingly still confluent and well attached to plate surface (Fig. 1.). Immunostaining for NSP 5a3a in non-treated cells localized NSP 5a3a to mostly the nucleus while in cells over-expressing NSP 5a3a, there seemed to be a greater distribution into the cytoplasm along with a seemingly increase staining in the nucleus as well as the presence

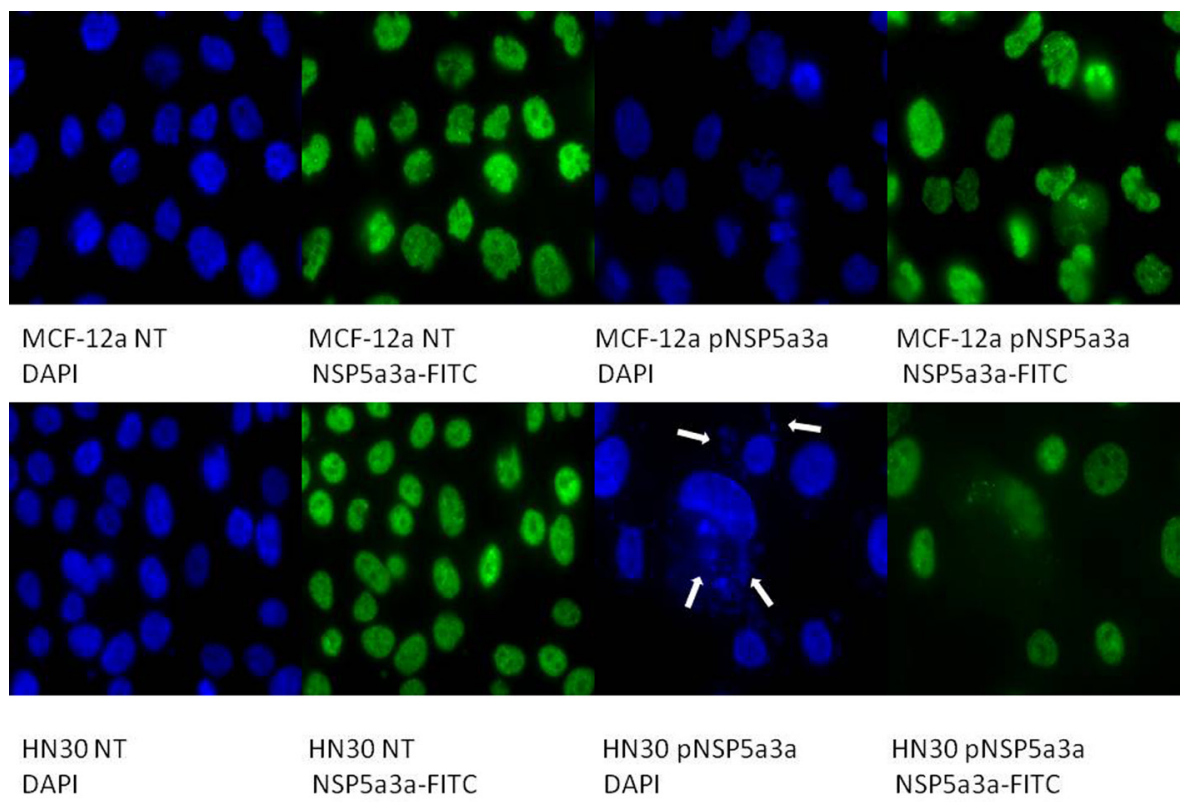

Figure 3: Immunostaining of HN30 and MCF-12 a cells for NSP 5a3a 3 days post-transfection. MCF-12a NT (DAPI): nontreated MCF-12a DAPI stained, MCF-12a NT (NSP 5a3a-FITC): non-treated MCF-12a FITC stained for NSP 5a3a, MCF-12a pNSP 5a3a (DAPI): MCF-12a transfected with pcDNA 3.0 NSP 5a3a DAPI stained, MCF-12a pNSP 5a3a (NSP 5a3a-FITC): MCF-12a transfected with pcDNA 3.0 NSP 5a3a FITC stained for NSP 5a3a, HN30 NT (DAPI): non-treated HN30 DAPI stained, HN30 NT (NSP 5a3a-FITC): non-treated HN30 FITC stained for NSP 5a3a, HN30 pNSP 5a3a (DAPI): HN30 transfected with pcDNA 3.0 NSP 5a3a DAPI stained, HN30 pNSP 5a3a (NSP 5a3a-FITC): HN30 transfected with pcDNA 3.0 NSP 5a3a FITC stained for NSP 5a3a. White arrows indicate apoptotic bodies. 
of possible protein aggregates containing NSP 5a3a with staining near and in likely association with apoptotic bodies. The cells over-expressing NSP 5a3a showed signs of apoptosis such as horse-shoe appearance of the nucleus and evidence of apoptotic bodies and blebs as indicated from the DAPI staining (Fig. 3). Immunostaining for $\mathrm{p} 73$ in non-treated cells localized p73 to mostly the nucleus with slight cytoplasmic staining while in cells over-expressing NSP $5 \mathrm{a} 3 \mathrm{a}$, there seemed to be a more diffuse distribution of p73 into the cytoplasm (Fig. 4). Immunostaining for TRAF2 in non-treated cells localized TRAF2 to both a diffuse localization in the cytoplasm and nucleus while in cells over-expressing NSP 5a3a, there seemed to be an increase of localization of TRAF2 into the cytoplasm as well as in association with protein bodies or aggregates as well as staining near and in likely association with apoptotic bodies (Fig. 5). Finally, immunostaining for TRADD in non-treated cells localized TRADD to mostly the nucleus while in cells over-expressing NSP 5a3a, there seemed to be an increase in the localization of TRADD in the cytoplasm, nucleus, and also in association with protein bodies or aggregates along with staining near and in likely association of apoptotic bodies (Fig. 6).

\section{Morphological and immunofluorescence analysis of MCF-12a over-expressing NSP 5a3a}

Asynchronous MCF-12a cells were transfected with pcDNA3.0 NSP 5a3a vector along with controls after which images of the cells were taken three days post-transfection and prepared for immune-staining to assess the effect of NSP 5a3a over-expression on protein distribution of NSP 5a3a, p73, TRAF2, and TRADD. Images of MCF-12a cells three days post-transfection revealed that treated cells with NSP 5a3a seemed quite confluent and well attached to the plate surface comparable to the controls (Fig. 2). Immunostaining for NSP 5a3a in non-treated cells localized NSP 5a3a to mostly the nucleus while in cells over-expressing NSP 5a3a, there seemed to be a similar distribution to mostly nuclear and nuclear integrity of cells over-expressing NSP 5a3a showed no evident signs of cellular membrane stress as compared to the non-treated cells (Fig. 3). Immunostaining for $\mathrm{p} 73$ in non-treated cells localized p73 to mostly the nucleus while in cells over-expressing NSP 5a3a, there seemed to be a more diffuse localization of p73 into the cytoplasm while still being quite nuclear (Fig. 4). Immunostaining for TRAF2 in non-treated cells localized TRAF2 to both a diffuse localization in the cytoplasm and nucleus while in cells over-expressing NSP 5a3a, there seemed to be an increase of localization of TRAF2 into the nucleus while still appearing in the cytoplasm (Fig. 5). Finally, immunostaining for TRADD in non-treated cells localized TRADD to mostly the nucleus while in cells over-expressing NSP 5a3a, there seemed to be a more diffuse localization of TRADD into the cytoplasm while still being localized in the nucleus (Fig. 6).

\section{Molecular analysis of NSP 5a3a over-expression in HN30}
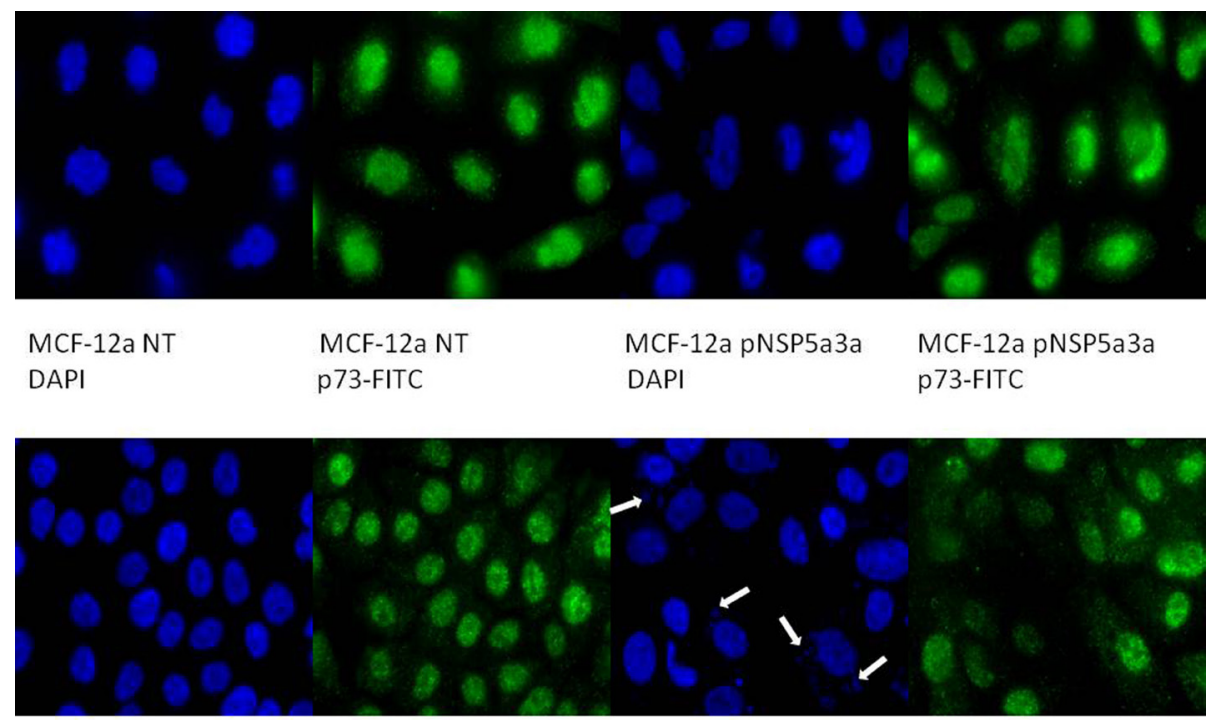

HN30 NT

HN30 NT

HN30 pNSP5a3a

HN30 pNSP5a3a

Figure 4: Immunostaining of HN30 and MCF-12a cells for p73 3 days post-transfection. MCF-12a NT (DAPI): non-treated MCF-12a DAPI stained, MCF-12a NT (p73-FITC): non-treated MCF-12a FITC stained for p73, MCF-12a pNSP 5a3a (DAPI): MCF-12a transfected with pcDNA 3.0 NSP 5a3a DAPI stained, MCF-12a pNSP 5a3a (p73-FITC): MCF-12a transfected with pcDNA 3.0 NSP 5a3a FITC stained for p73, HN30 NT (DAPI): non-treated HN30 DAPI stained, HN30 NT (p73-FITC): non-treated HN30 FITC stained for p73, HN30 pNSP 5a3a (DAPI): HN30 transfected with pcDNA 3.0 NSP 5a3a DAPI stained, HN30 pNSP 5a3a (p73-FITC): HN30 transfected with pcDNA 3.0 NSP 5a3a FITC stained for p73. White arrows indicate apoptotic bodies. 


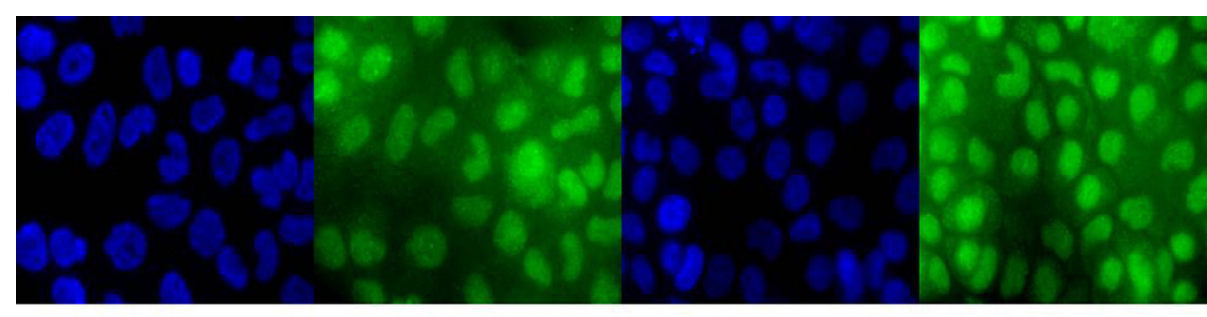

$\begin{array}{llll}\text { MCF-12a NT } & \text { MCF-12a NT } & \text { MCF-12a pNSP5a3a } & \text { MCF-12a pNSP5a3a } \\ \text { DAPI } & \text { TRAF2-FITC } & \text { DAPI } & \text { TRAF2-FITC }\end{array}$

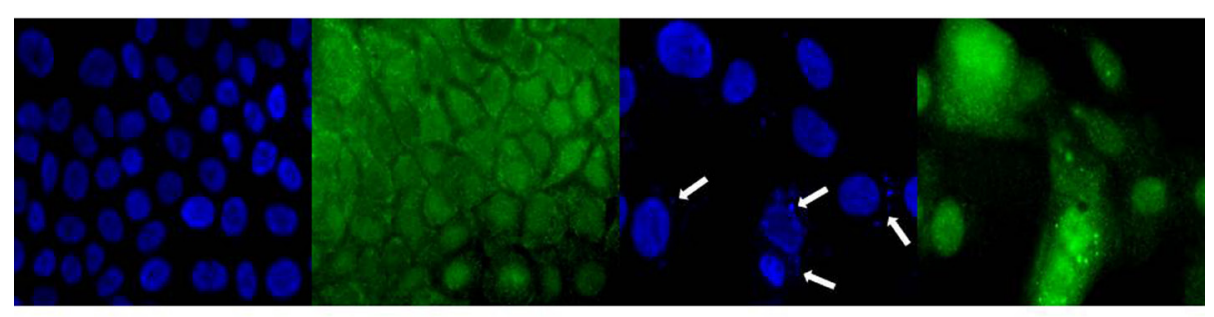

\begin{tabular}{|c|c|c|c|}
\hline HN30NT & HN30 NT & HN30 pNSP5a3a & HN30 pNSP5a3a \\
\hline DAPI & TRAF2-FITC & DAPI & TRAF2-FITC \\
\hline
\end{tabular}

Figure 5: Immunostaining of $\mathrm{HN} 30$ and MCF-12a cells for TRAF2 3 days post-transfection. MCF-12a NT (DAPI): nontreated MCF-12a DAPI stained, MCF-12a NT (TRAF2-FITC): non-treated MCF-12a FITC stained for TRAF2, MCF-12a pNSP 5a3a (DAPI): MCF-12a transfected with pcDNA 3.0 NSP 5a3a DAPI stained, MCF-12a pNSP 5a3a (TRAF2-FITC): MCF-12a transfected with pcDNA 3.0 NSP 5a3a FITC stained for Traf-2, HN30 NT (DAPI): non-treated HN30 DAPI stained, HN30 NT (TRAF2-FITC): non-treated HN30 FITC stained for TRAF2, HN30 pNSP 5a3a (DAPI): HN30 transfected with pcDNA 3.0 NSP 5a3a DAPI stained, HN30 pNSP 5a3a (TRAF2-FITC): HN30 transfected with pcDNA 3.0 NSP 5a3a FITC stained for TRAF2. White arrows indicate apoptotic bodies.

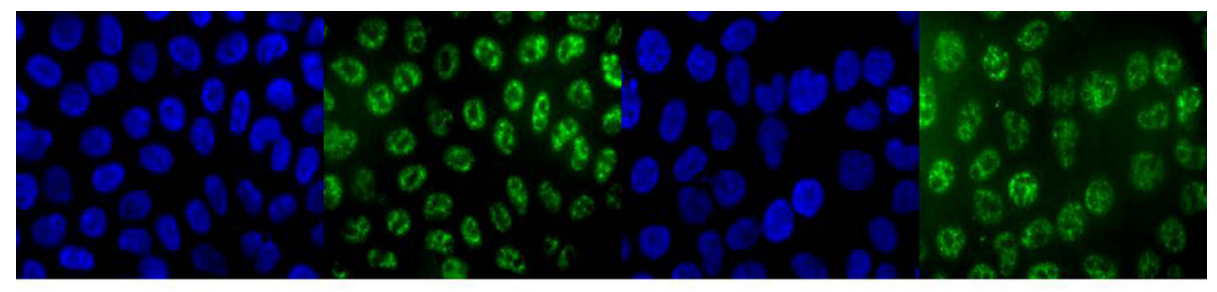

$\begin{array}{llll}\text { MCF-12a NT } & \text { MCF-12a NT } & \text { MCF-12a pNSP5a3a } & \text { MCF-12a pNSP5a3a } \\ \text { DAPI } & \text { Tradd-FITC } & \text { DAPI } & \text { Tradd-FITC }\end{array}$

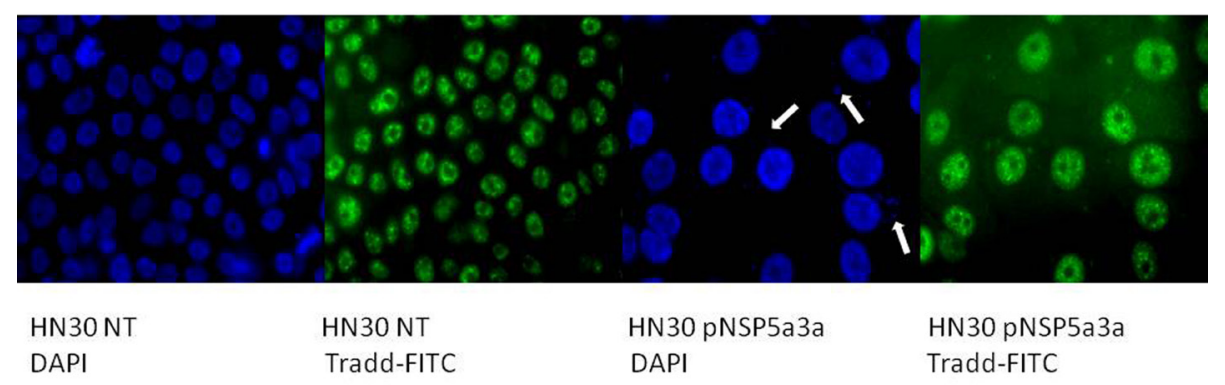

Figure 6: Immunostaining of HN30 and MCF-12a cells for TRADD 3 days post-transfection. MCF-12a NT (DAPI): nontreated MCF-12a DAPI stained, MCF-12a NT (TRADD-FITC): non-treated MCF-12a FITC stained for TRADD, MCF-12a pNSP 5a3a (DAPI): MCF-12a transfected with pcDNA 3.0 NSP 5a3a DAPI stained, MCF-12a pNSP 5a3a (TRADD-FITC): MCF-12a transfected with pcDNA 3.0 NSP 5a3a FITC stained for Tradd, HN30 NT (DAPI): non-treated HN30 DAPI stained, HN30 NT (TRADD-FITC): non-treated HN30 FITC stained for TRADD, HN30 pNSP 5a3a (DAPI): HN30 transfected with pcDNA 3.0 NSP 5a3a DAPI stained, HN30 pNSP 5a3a (TRADD-FITC): HN30 transfected with pcDNA 3.0 NSP 5a3a FITC stained for TRADD. White arrows indicate apoptotic bodies. 
Western blot analysis of total lysates of HN30 cells from three days post-transfection along with controls were analyzed to better understand and explain the mechanism that NSP 5a3a may be involved to induce apoptosis as previously described in the HN30 cell line[28]. We considered and examined apoptotic proteins belonging to the caspase family that were not previously investigated in addition to proteins associated with the TNF signaling pathway such as TRAF-2 and TRADD. This was done so in light of the fact that NSP 5a3a over-expression was shown to affect the expression levels of p73 [7] while p73 has been suggested to be regulated by death receptor

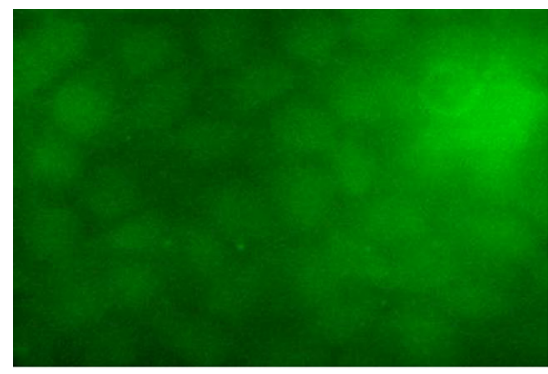

MCF-12a secondary FITC Only

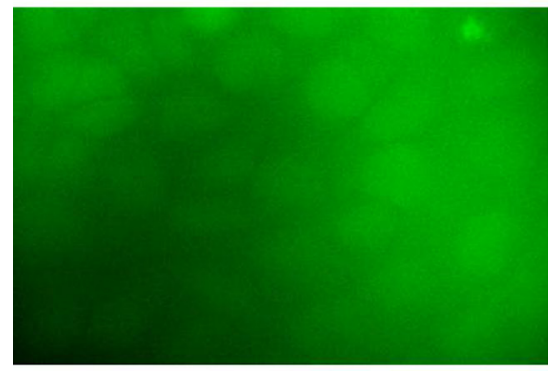

HN30 secondary FITC Only signaling pathways involving Daxx [72] but also given the fact that potential binding motifs had been previously found on NSP 5a3a for apoptotic proteins associated with TNF/death receptor signaling [7]. TRADD levels seemed apparently the same between treated and controls. TRAF2 levels demonstrated a slight increase in a $190 \mathrm{kDa}$ band in the transfected cells with a slight decrease in the 130 and $112 \mathrm{kDa}$ bands in the treated cells compared to the controls. Though, interestingly there was a moderate increase in the $55 \mathrm{kDa}$ band compared to the controls while a $45 \mathrm{kDa}$ band was comparable between transfected and controls. P73 levels demonstrated a significant decrease in

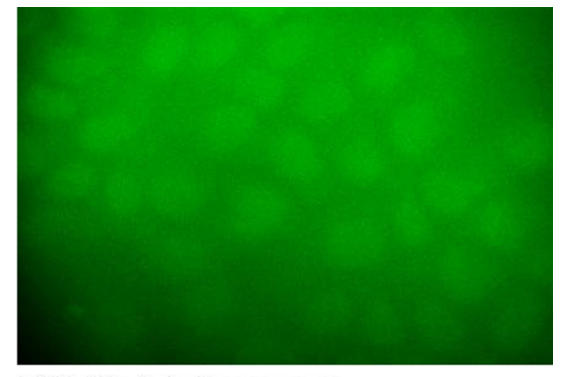

MCF-12a Autofluorescence

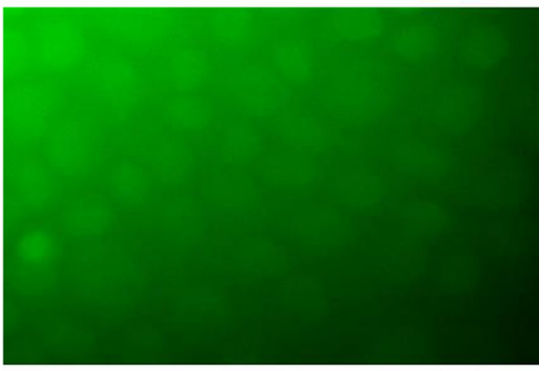

HN30 Autofluorescence

Figure 7: Immunostaining controls of $\mathrm{HN30}$ and MCF-12a cells for secondary anti-rabbit FITC and autofluorescence.

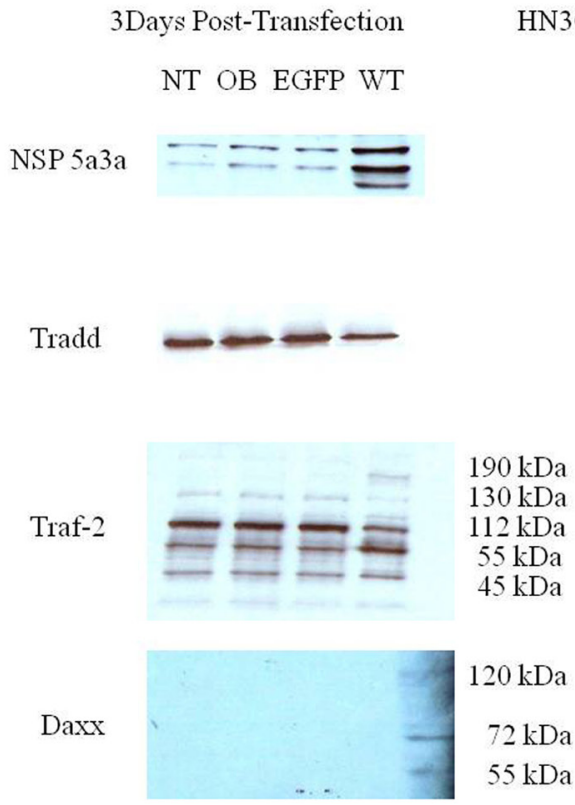

3Days Post-Transfection NT OB EGFP WT

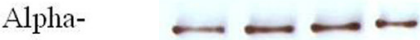
tubulin
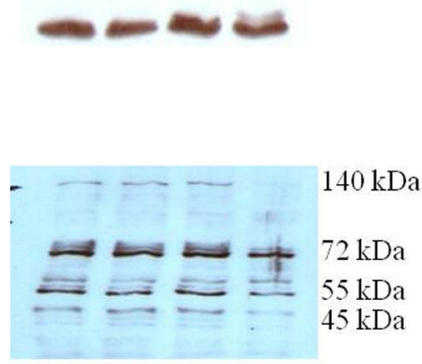

Figure 8: Western Blot analysis of total lysates from asynchronous HN30 cells 3 days post-transfection. NT: non-treated, OB: only buffer, EGFP: only pcDNA3.1/CT-GFP vector, NSP 5a3a/EGFP: pcDNA 3.1/CT-GFP and pcDNA 3.0 NSP 5a3a. 
the $140 \mathrm{kDa}$ bands in transfected cells along with a slight decrease in a $55 \mathrm{kDa}$ band and significant decrease in a 45 $\mathrm{kDa}$ bands in treated cells compared to the controls. The $72 \mathrm{kDa}$ band remained comparable between treated and controls. B23 levels were seemingly unaffected between treated and controls. DAXX levels were not detected in controls though a band approximately around 72-75 $\mathrm{kDa}$ was detected in transfected HN30 cells showing a significant increase compared to controls as well as bands around 55 and $120 \mathrm{kDa}$ were detected in transfected cells

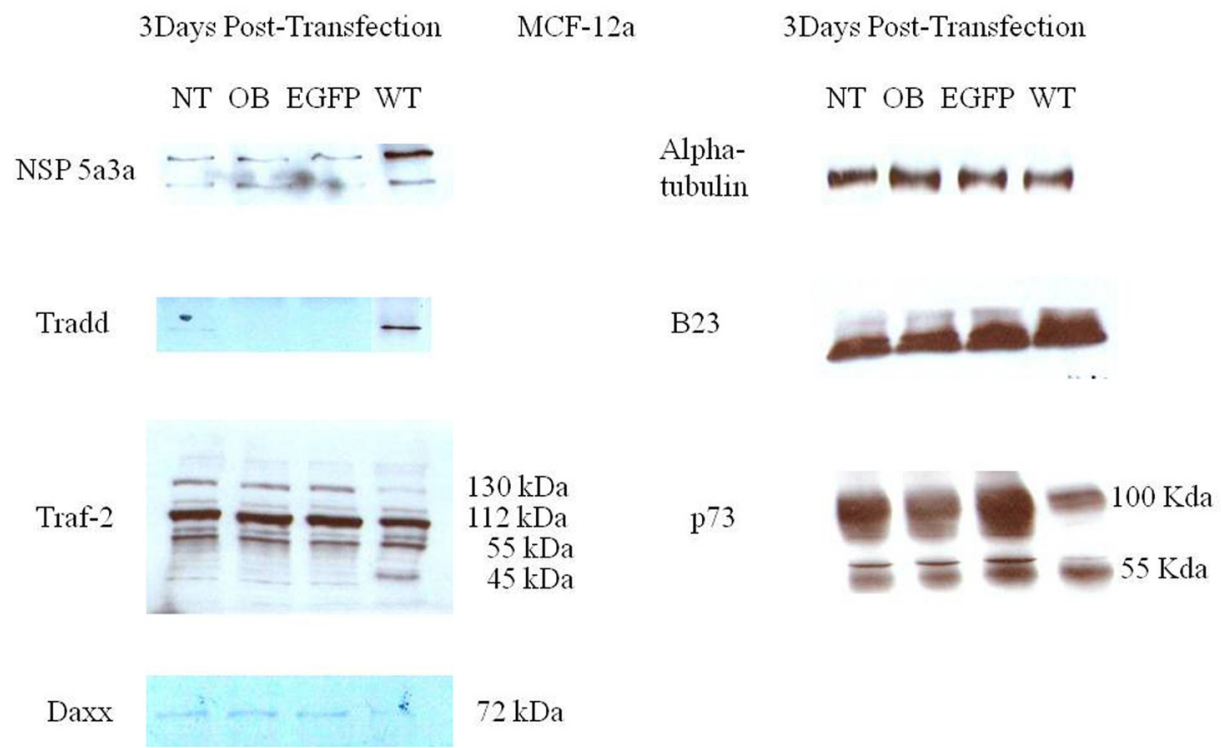

Figure 9: Western Blot analysis of total lysates from asynchronous MCF-12a cells 3 days post-transfection. NT: nontreated, OB: only buffer, EGFP: only pcDNA3.1/CT-GFP vector, NSP 5a3a/EGFP: pcDNA 3.1/CT-GFP and pcDNA 3.0 NSP 5a3a.

a.

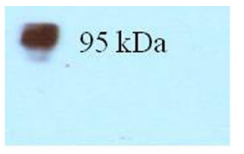

HN30 NT Pre-

IPNSP Cleared

WB DAXX

c.

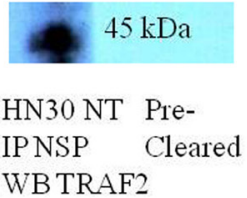

e

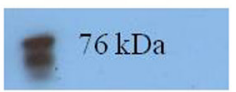

HN30 NT Pre-

IPDAXX/Cleared

IPTRAF2

WB NSP b.

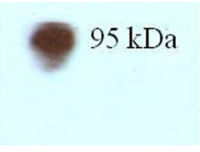

HN30 TRD Pre-

IPNSP Cleared

WB DAXX

d.

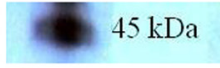

HN30 TRD Pre-

IPNSP Cleared

WBTRAF2

f.

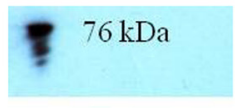

HN30 TRD Pre-

IPDAXX/ Cleared

IPTRAF2

WB NSP

Figure 10: Western blot analysis of co-immunoprecipitations of asynchronous HN30 non-treated and HN30 cells transfected with pcDNA 3.0 NSP 5a3a and pcDNA 3.1/CT-GFP for 3 days. NT: non-treated HN30 cells, TRD: HN30 cells over-expressing NSP 5a3a. a. Immunoprecipitation of non-treated HN30 cells using rabbit anti-NSP 5a3a and western blot analysis using rabbit anti-DAXX., b. Immunoprecipitation of HN30 treated cells using rabbit anti-NSP 5a3a and western blot anaylsis using rabbit anti-DAXX., c. Immunoprecipitation of non-treated HN30 cells using rabbit anti-NSP 5a3a and western blot analysis using rabbit antiTRAF2., d. Immunoprecipitation of HN30 treated cells using rabbit anti-NSP 5a3a and western blot analysis using rabbit anti-TRAF2., e. Immunoprecipitation of non-treated HN30 cells using rabbit anti-TRAF2/DAXX and western blot analysis using rabbit anti-NSP 5a3a, and $\mathrm{f}$. Immunoprecipitation of HN30 treated cells using rabbit anti-TRAF2/DAXX and western blot analysis using rabbit anti-NSP 5a3a. 
but not detected in the controls. Also interestingly, NSP $5 \mathrm{a} 3 \mathrm{a}$ levels showed the appearance of a lower band around around 55 to $60 \mathrm{kDa}$ range in the transfected cells (Fig. 8). Cleaved caspase 7, 8, 9, and 1 were not detected in both transfected and controls (data not shown).

\section{Molecular analysis of NSP 5a3a over-expression in MCF-12a}

Western blot analysis of total lysates of MCF12a cells from three days post-transfection along with controls were analyzed to explain the absence of observed apoptosis in this particular normal cell line in contrast to the observed apoptosis seen in the previous control cell WI-38 when NSP 5a3a was over-expressed [7]. TRADD levels showed a significant increase in transfected cells compared to controls while in controls the TRADD levels were barely if at all detectable. TRAF2 levels showed a slight decrease in the $130 \mathrm{kDa}$ band in transfected cells compared to controls. Bands detected at the $112 \mathrm{kDa}$ and $55 \mathrm{kDa}$ range were comparable between transfected and controls. A slight increase in a $45 \mathrm{kDa}$ band was detected in the transfected compared to controls. P73 levels showed a moderate to significant decrease in a $100 \mathrm{kDa}$ band and a slight to moderate decrease in the $55 \mathrm{kDa}$ in transfected cells compared to the controls. DAXX levels were detected at seemingly low levels around 72-75 kDa in controls though showed a decrease in the transfected cells being undetectable. B23 levels seemed moderately increased in transfected cells compared to the controls. There was no evidence of a lower molecular weight band for NSP 5a3a in the transfected cells (Fig. 9). Again, cleaved caspases 7, 8, 9, and 1 were tested and not detected for both transfected and controls (data not shown).

\section{Molecular analysis of Co-immunoprecipitations in non-treated and NSP 5a3a over-expressing HN30 cells}

Western blot analysis of non-treated HN30 cells revealed an interaction between NSP 5a3a and DAXX/ TRAF2 as well as an interaction between NSP 5a3a and DAXX/TRAF2 in apoptotic cells over-expressing NSP 5a3a in which we detected a $95 \mathrm{kDa}$ band for DAXX and a $45 \mathrm{kDa}$ band for TRAF2 (Fig. 10). Intensity of the bands for NSP 5a3a, DAXX, and TRAF2 seem slightly more intense in the transfected cells over-expressing NSP 5a3a compared to the non-treated cells though in the case of the NSP 5a3a, which still exhibits the doublet as in the Western blots of the total lysates of HN30 (Fig. 8), the lower molecular weight band seems less intense in the treated cells.

\section{DISCUSSION}

Programmed cell death, also known as apoptosis, is an active daily process within tissues and organs, necessary to ensure the proper functioning of the entire organism being critical for the regulation of development during growth and eventual homeostasis of tissues later in life. This finely tuned balance between cell death and proliferation results from the role of apoptosis in our normal physiological cellular turn-over and maintenance of organ functionality. When this process of apoptosis is unbalanced or unregulated, serious pathological conditions can arise. Whole tissue and organ death have been associated with cardiovascular events such as heart attacks and strokes, while slower cellular death as been associated with particular neurodegenerative diseases such as dementia and Parkinsons [79-80].

Cancer cells seem to have escaped a limited lifespan, evading natural cell turn over and self-destruction by silencing various endogenous executors and stimulators of apoptosis. It seems a fair assessment that the majority of modern day illnesses are associated with dysregulation of the apoptosis, either being over-activated or underactivated depending on the pathology [79-80]. The cancer cells usually suppress apoptosis by three fundamental mechanisms: prevention of pro-caspase activation; neutralization of activated caspases; and silencing of caspase and caspase-like expression at the gene level. Many forms of cancer including leukemia, exhibit overexpression of IAPs (inhibitors of apoptosis) such as c-FLIP and CARD, which can both directly interact with endogenous caspases and regulate their activation in a negative manner, thereby impairing the necessary proteolytic cascade essential for apoptosis. Thus, apoptotic extrinsic pathways involving TNFR/TRAIL-R as well as intrinsic pathways involving cytochrome $\mathrm{c}$ and AIF, through caspase dependent and independent mechanisms respectively via the mitochondria can all be abrogated by cancer cells in addition to their ability to alter expression levels and function of anti-apoptotic proteins such as Bcl2 family members [41, 79-81].

The recent investigative effort in the past decade and half in molecular mechanisms and modulators of apoptosis has generated a greater understanding of this complex biological process and its association with disease in the human body which as a result has pushed for the on-going development of novel strategies targeting various key components of the apoptotic process either in a pro-apoptotic or anti-apoptotic manner. Present ongoing apoptotic therapies targeting death receptors have included TRAIL through use of TRAIL-R1/R2 monoclonal antibodies as well as soluble Apo2L/TRAIL, in which most of these therapies have progressed to Phase 1 with exception of the Apo2L/TRAIL. Other apoptotic strategies so far have included targeting caspases such as caspase 1, 3,6 , and 9 through activators of the caspase or inhibitor of the caspase's inhibitor, as well targeting IAPs/SMAC by use of non-peptide small molecules or antisense oligos 
most of which have remained pre-clinical. There has been also development of small molecule inhibitors as well as use of natural and synthetic compounds in targeting Bcl2 anti-apoptotic members which have remained mostly preclinical with the exception of a particular antisense oligo in Phase 3 for treatment of leukemia, melanoma, multiple myelomas, and non-small lung cancer [80-81].

There has been development of p53 targeted adenoviral therapies to re-introduce wild type p53 which have reached phase 3 in treatment of Head and Neck cancer including other solid tumors as well as a phase $2 / 3$ combination therapy of advanced squamous cell cancer again using genetically engineered adenovirus ONYX15 [80]. Though, despite the primary advantages of this system being high level of transduction, high level of gene expression, and being able to infect a broad spectrum of cell types there are setbacks and issues still being addressed and being investigated regarding the issues of developing more cell/tissue specific vectors with minimal host immune/inflammatory responses and cytotoxicity as well as the preventing the generation of a replication competent virus, there still is need to consider and develop further alternative therapeutic approaches via non-viral methods [82].

This subsequent study has revealed an interesting and novel mechanism by which this unique structural protein NSP 5a3a induces apoptosis in HN30 cells lines, by seemingly stimulating extrinsic pathways of apoptosis internally, through two signaling events, one most likely involving p73/DAXX and the other involving TRAF2/ TRADD.

HN30 cells over-expressing NSP 5a3a showed clearly cellular stress from apoptosis (Fig. 1) further more evident in the immunostaining of these cells (Fig. 3-6) and as in our previous study, a significant decrease in a higher molecular weight p73 isoform at $140 \mathrm{kDa}$ [7] was detected while there was also significant decrease in a $45 \mathrm{kDa}$ isoform along with a $55 \mathrm{kDa}$ isoform to a lesser extent. Additionally, a $72 \mathrm{kDa}$ isoform was also detected though seemed comparable in levels between controls and treated cells over-expressing NSP 5a3a (Fig. 8). Since the N-terminal truncated p73 isoforms such as delta Np73, ex2p73, and ex2/3p73, have been found to be highly expressed in many cancers and known to possess anti-apoptotic activities [83], it's reasonable that in fact the isoforms of lower molecular weight we see being down-regulated or perhaps degraded are in fact anti-apoptotic which would make sense given the cellular response we observe when over-expressing NSP 5a3a. The fact we used two anti-p73 antibodies (Santa Cruz H-79) and (Santa Cruz S-20) in this study, we would expect a greater degree of detection and perhaps specificity of other isoforms not previously detected by the (Santa Cruz H-79) antibody alone. Typically, the TAp73 isoforms such as: alpha, beta, gamma, and delta are linked to cell cycle arrest and apoptosis though which cell fate is determined depends on the cell type and also activating p53 target genes are activated and in which cell type [84]. Usually, apoptosis is evident by an upregulation of a TAp73 isoform as seen with TAp73 alpha and Tap73 beta [84]. Previously, it was suggested that the $140 \mathrm{kDa}$ along with the $72 \mathrm{kDa}$ isoforms may be a result of some post-translational modification of a p73 isoform, since higher molecular weight isoforms of $\mathrm{p} 73$ have been identified around 75,90 and $140 \mathrm{kDa}$ in specific regions of adult human brain [85]. Since it has been shown that p73 can be ubiquitinated, in particular TAp73a and deltaNp73 isoforms can be ubiquitinated by Itch, which results in proteasomal-dependent degradation of these p 73 isoforms [86-87], it is plausible that the higher molecular weight of $140 \mathrm{kDa}$ we observe may be the apoptotic form of $\mathrm{p} 73$, possibly being $\mathrm{p} 73 \mathrm{a}$ that is polyubiquitinated in the controls while in the cells over-expressing NSP $5 \mathrm{a} 3 \mathrm{a}$, there is a decrease in its polyubiquitinated form resulting in more of the apoptotic isoform being present and stable to promote its activity. While MCF-12a cells over-expressing NSP 5a3a did not exhibit cellular stress being apoptotic in appearance as evident in (Fig. 2) and the immunostaining (Fig. 3-6), the MCF-12a cells showed a $55 \mathrm{kDa}$ isoform being down-regulated in cells over-expressing NSP 5a3a (Fig. 9) though we cannot be certain if in fact this isoform is the same as the one observed in the HN30 cells, but is plausible since both apoptotic and anti-apoptotic functions have been assigned to these deltaNp73 isoforms $[83,88]$ and interestingly, we observed a $100 \mathrm{kDa}$ isoform being down-regulated in the MCF-12a cells over-expressing NSP 5a3a (Fig. 9), which again may be a post-translational modification such as ubiquitination of an anti-apoptotic form of p73 though in all cases, until more specific antibodies for such posttranslational modifications are tested, we cannot be sure of the exact nature of the type of covalent modification to these isoforms. The same plausibility would hold also in the case of sumoylation of $\mathrm{p} 73$, since it has been reported that for example SUMO-1 does covalently modify both full length TA p73a and deltaNp73a isoforms. While usually sumoylation has been associated with different cellular processes such as transcriptional regulation, subcellular transport regulation, influence protein stability and protein function in both cell cycle and apoptosis, in the case of p73a, its sumoylation has been associated with alteration in its subcellular localization and subsequent degradation [89-90].

In our previous study, we had found by use of a motif finder at http://motif.genome.jp/ a potential interaction site in NSP 5a3a with DAXX at at amino acid site: 276-330 and thus wanted to confirm if such an interaction existed between the two proteins also given that fact that DAXX was known to be involved in the death doman receptor signaling pathway involving Fas [91]. Co-immunoprecipitations of HN30 non-treated and treated cells over-expressing NSP 5a3a revealed an interaction between NSP 5a3a and 
DAXX while seemingly more intense in treated cells with a band at approximately $95 \mathrm{kDa}$ (Fig. 10). DAXX has been reported to act as a transcriptional repressor of many DNA-binding proteins [92-93], while it has been linked to both apoptotic and anti-apoptotic roles [91, 94] where silencing of DAXX sensitized cells to both Fas and stress-induced apoptosis [95]. In regards to its apoptotic role, DAXX has been associated with FAS signaling, linking that signaling to the JNK pathway through ASK1 activation. Normally, DAXX is predominantly nuclear acting as a transcriptional repressor in the nucleus though under apoptotic conditions in which it mediates its effect through ASK1, it shuttles to the cytoplasm thus promoting caspase-independent apoptosis is promoted [96-99]. Interestingly, DAXX has been reported to interact with P73 acting as a transcriptional co-repressor of p53 and its members, by which this regulation is modulated by PML (promyelocytic leukemia protein) occurring in nuclear PODs (PML oncogenic domains) [100]. HN30 cells overexpressing NSP 5a3a showed a significant increase in DAXX with observation of a band between 72-75 $\mathrm{kDa}$ and a band between 120-130 kDa while being undetectable in controls (Fig. 8 ), and in fact similar distinct migratory DAXX forms have been reported in which a $70 \mathrm{kDa}$ form was known to be non-phosphorylated and known to have transcriptional co-repressor activity as also a $97 \mathrm{kDa}$ and $120 \mathrm{kDa}$ bands have been identified relating to DAXX while the $120 \mathrm{kDa}$ was revealed to be a result in part of a post-translational modification involving phosphorylation [101]. It is likely the $95 \mathrm{kDa}$ may also be in part to a posttranslational modification in the conditions we observed. A similar band of $72-75 \mathrm{kDa}$ was observed in controls of the MCF-12a though fairly weak and being nearly undetectable in MCF-12a cells over-expressing NSP 5a3a (Fig. 9). While we also detected a much lower band around $55 \mathrm{kDa}$ in the HN30 treated cells we cannot be certain if this represents a non-specific band or perhaps some fragment of DAXX. Immunostaining of HN30 cells over-expressing NSP 5a3a showed a seemingly increased distribution of p73 from the nucleus into the cytoplasm, though not as quite as diffuse into the cytoplasm as the MCF-12a cells over-expressing NSP 5a3a (Fig. 4). Since the antibody used for the immunostaining for p73 was the rabbit polyclonal p73 (Santa Cruz H-79) and even though according the manufacturer the antibody should be able to recognize not only the apoptotic TAp73 isoforms $(\alpha, \beta, \gamma, \delta, \varepsilon, \eta, \zeta)$ [83] if expressed but also the anti-apoptotic forms ex2p73 $(\alpha, \beta, \gamma, \delta, \varepsilon, \eta, \zeta)$ and ex $2 / 3 \mathrm{p} 73$ $(\alpha, \beta, \gamma, \delta, \varepsilon, \eta, \zeta)[83]$, we were unable in our previous study to detect any bands that corresponded to those isoforms. Even though it is possible that this particular antibody may behave differently given the application it is used for thus allowing for different specificity and sensitivity, we cannot be sure if what we see by the immunostaining is solely the higher molecular weight isoform of $140 \mathrm{kDa}$ in the case of the HN30 cells over-expressing NSP 5a3a.
It's been reported that TAp73 can localize in both the cytoplasm and nucleus while the deltaNp73 forms tend to localize mostly in the nucleus as seen in-vivo in breast and non-small lung cancer [102-103]. TAp73 and deltaNp73 have been seen mostly in nuclear compartments invitro though there has been variation in its localization with limited cytoplasmic localization being mostly nuclear to even being exclusively cytoplasmic as seen in medullobastoma cell lines [104]. It is possible that we are observing an increased translocation of $\mathrm{p} 73$ from the nucleus to the cytoplasm due to an increase ubiquitination of the a particular p73 isoform/s, since it's been shown that p73 is ubiquitinated in the nucleus, this process regulated by PML and thus then shuttles to the cytoplasm for proteasomal degradation though cannot exclude should this particular p73 isoform/s may be instead sumoylated which can lead to proteasomal degradation as well [86, 105] as also transcriptional repression involving DAXX in PODs [100]. Then again, p73 has been known to interact with DAXX and it has been suggested that p53/p73 may potentiate DAXX's pro-apoptotic function when $\mathrm{p} 53 / \mathrm{p} 73$ associate with DAXX in the PODs of the nucleus [106]. Since we do not know the behavior of DAXX during over-expression of NSP 5a3a nor its interaction with $\mathrm{p} 73$ if still occurring in PODs regions of the nucleus or in other compartments, further study in needed to elucidate this likely signaling interaction involving p73 and DAXX. Thus, it is possible that NSP 5a3a may be assisting DAXX to regulate particular p73 isoforms perhaps in a negative manner in the PODs while enhancing its apoptotic activity with other p73 isoforms depending on the cell type, cellular events in action and compartments in which they find themselves, yet also assisting DAXX to interact with other apoptotic proteins most likely in the ASK1-JNK pathway in parallel. Given, that in our previous study we had detected a Parp cleavage product of $89 \mathrm{kDa}$ in HN30 cells over-expressing NSP 5a3a, which typically is associated with caspase activation in-vitro usually by caspase 3 as well as other caspases if caspase 3 is not available [107], we could not confirm any such activation and having been already documented of the existence of Parp cleavage associated with caspase 3 independent activation [108-109] we further tested in this study if there was activation of other canonical caspases such as caspase 9, 8, 7 and 1, in which we were not able to detect any cleaved products hence caspase activation which seems to point more in favor of a caspase independent mechanism, which has been associated with DAXX activation of the ASK1-JNK pathway [110]. Though Parp cleavage is known as classical apoptotic hallmark [111] and it has been documented that DAXX ectopic over-expression has been associated with caspase dependent activation by FAS and TRAIL induced apoptosis [112] one cannot exclude that depending on the cell system and apoptotic conditions being investigated that perhaps through NSP 5a3a over-expression, DAXX may be involved in a 
caspase independent activation of JNK pathway with Parp cleavage since Parp cleavage has been seen independent of caspase activation [113-115]. Furthermore, given that an interaction between NSP 5a3a and a higher molecular weight of DAXX at $95 \mathrm{kDa}$ was confirmed while modulation in a $72-75 \mathrm{kDa}$ band as well as a $120-130 \mathrm{kDa}$ was detected in the HN30 treated cells, this may indicate that NSP 5a3a preferentially interacts with a particular post-translational form of DAXX which may contribute to regulation and stability of the other DAXX un-modified and modified forms post-translationally.

When we examined for other members involved in the ASK1-JNK pathway, we found by use of ELM motif finder at http://elm.eu.org/ potential sites on NSP 5a3a for interaction with TRAF2 at amino acid sites: $376-379$ (TTQE) and 455-458 (TLEE) as well as able to identify another nine potential TRAF2 consensus interaction sequences being the (SXXE) motif [116] in NSP 5a3. We thus were able to confirm an interaction between NSP 5a3a and TRAF2 in both HN30 cells over-expressing NSP 5a3a and non-treated cells, identifying in both cases a band approximately $45 \mathrm{kDa}$ (Fig. 10). HN30 cells over-expressing NSP 5a3a showed a slight decrease in 112 and $130 \mathrm{kDa}$ isoforms compared to controls with a slight increase in a $190 \mathrm{kDa}$ isoform and more moderate increase in a $55 \mathrm{kDa}$ isoform compared to controls (Fig. 8). We also observed a $45 \mathrm{kDa}$ isoform which showed no apparent change in levels between treated and controls (Fig. 8). Similar bands were identified in MCF-12a cells though with a different pattern of expression in which a $130 \mathrm{kDa}$ isoform was slightly decreased in MCF-12a cells over-expressing NSP 5a3a while the $112 \mathrm{kDa}$ and $55 \mathrm{kDa}$ isoforms remained apparently the same between treated cells and controls (Fig. 9). The lower molecular weight $45 \mathrm{kDa}$ isoform seemed slightly increased in MCF-12a cells over-expressing NSP 5a3a (Fig. 9). We can expect to see a broad range of isoforms since we used a rabbit polyclonal TRAF2 (Novus NB100-56173) antibody that has been documented to be able to detect a broad range of TRAF2 isoforms again depending on cell type and conditions. TRAF2 has been known well to be involved in the NF-KB pathway, both as positive regulator of the canonical pathway and as a negative regulator as well, in which depending on cell type and signaling intermediates and adaptors available it can favor or not cellular proliferation and survival $[54,117]$. Though, it has been reported that TRAF2 can be involved in JNK activation leading to apoptosis by TNFa induction [118], by which TRAF2 can be polyubiquitinated at K63 resulting in its degradation and translocation to the cytoplasmic insoluble membrane fraction and cytoskeletal one as well $[54,119-$ 120]. Interestingly, we see modulation in protein levels of TRAF2 of both high and low molecular weight isoforms in the HN30 cells over-expressing NSP 5a3a, in which the higher molecular weight isoforms may be in fact post-translational modifications of TRAF2 lower weight isoforms resulting in polyubiquitination and given the fact we see an increased immunostaining for TRAF2 in the cytoplasm and association with likely apoptotic bodies as well (Fig. 5), it would seem plausible to support the idea that TRAF2 may be involved in mediating apoptotic signaling thru interaction of NSP $5 \mathrm{a} 3 \mathrm{a}$ which could serve as a signaling scaffold for TRAF2 isoforms. It's been suggested that TRAF2 localization in the nucleus may be linked to transcriptional regulation while in the cytoplasm it may be linked to signal transduction [121]. In contrast, MCF-12a cells exhibited a more nuclear staining in the cells over-expressing NSP 5a3a compared to its controls though with lesser staining in the cytoplasm compared to the treated HN30 cells (Fig. 5). Even though both cell types expressed similar isoforms, it seems that in the MCF-12a the over-expression of NSP 5a3a did not induce the same intracellular stress response resulting in apoptosis, though in the case of the MCF-12a, the TRAF2 may be involved in activation or regulation of proteins involved in the NF$\mathrm{KB}$ pathway for example, leading to either

prosurvival or cell cycle arrest. This we cannot be sure of in the case of the MCF-12a, since we would need further study of the cell cycle during over-expression of NSP 5a3a and analysis of NF-KB pathway members as well. Even though, NF-KB signaling has been found to be involved in apoptosis depending on the nature of the apoptotic stimuli [122-123] it usually involves the repression or down-regulation of target genes including TRAF2 [124], which ultimately makes more favorable the implication of TRAF2 in association with NSP 5a3a in the induction of apoptosis in HN30, whether the signal is being mediated through ASK1 leading to JNK activation or even through RIP which can lead to JNK activation and apoptosis also [125-126].

Another TNFR signaling protein known to interact with TRAF2 is TRADD particular to the TNFR1 pathway which can depending with which signaling and adaptor proteins it interacts with, it can either be involved in NF$\mathrm{kB}$ activation thru binding with TRAF2 or activation of apoptosis thru interaction with FADD [127-128]. While the levels of TRADD seemed comparable between controls and HN30 cells over-expressing NSP 5a3a (Fig. 8) there was an evident change in the distribution of TRADD as indicated by the immunostaining (Fig. 6) being more nuclear as well as more cytoplasmic in treated cells along with association with apoptotic bodies. In contrast, a significant increase in TRADD expression was detected in MCF-12a cells over-expressing NSP 5a3a while being undetectable in the control (Fig. 9) though we still observed its expression in controls by immunostaining indicating a likely difference in sensitivity both in the behavior of the antibody used as well as the application. There seemed to me a more diffuse staining of TRADD into the cytoplasm of the MCF-12a treated cells compared to the controls, while still be mostly nuclear in both cases. While TRADD depending 
on its location in the cell can induce apoptosis by different mechanisms, either through a FADD/caspase 8 pathway in the cytoplasm or through caspase 9 activation when in the nucleus [129], in both cases we exclude such pathways since we were unable to detect caspase $8 / 9$ activation in the HN30 treated cells. The fact we see appreciable expression levels of both TRADD and TRAF2 in the controls of the HN30 cells is of interest since it has been reported that the TNFR1-TRADD-TRAF2-RIP pathway is switched on in head and neck cell carcinoma leading to NF-kB constitutive activation and hence cell survival and proliferation [130]. Given this cellular behavior of the head and neck carcinoma in which this particular signaling pathway is already activated, it is plausible that NSP 5a3a may be altering this signaling pathway in favor of apoptosis through use of TRAF2 and TRADD. While in the MCF-12a cells, not showing the same cellular stress as in the HN30, NSP 5a3a-TRAF2 could be interacting with TRADD in promoting cell growth arrest or survival through the NF-kB pathway. Since we do not know the dynamics of interaction between TRADD and TRAF2 in the apoptotic conditions we observed, we cannot be sure if there is a novel interaction between TRADD and TRAF2 mediated by NSP 5a3a that is involved in the promoting the apoptosis thru the ASK1/JNK pathway. Even though it has been shown that TRADD-TRAF2 interaction in the TNFR1 signaling pathway leads to NF-kB activation and cell survival, such that TRAF2 is not essential for TNFR1 apoptotic signaling $[117,131]$ we cannot exclude a possible undefined interaction between NSP 5a3a/TRAF2 with TRADD and other signaling and adaptor proteins that would allow the cells to die by apoptosis. Interestingly, though there no evident change in expression in the B23 levels in H30 cells over-expressing NSP 5a3a, as seen reported in our previous study [7], we did observe a moderate increase in B23 levels in the MCF-12a cells over-expressing NSP 5a3a which may be contributing to the observed non-stressed and non-apoptotic state of these cells since B23 over-expression has been associated with cell cycle arrest and proliferation [132-133] though again we cannot be sure if the cells are in fact arrested in particular phase of the cell cycle though given the expression of B23 along with TRADD and TRAF2 in the MCF-12a. Though, one cannot rule out that in this particular normal cell line, there may be a short circuit or interruption of induction of apoptosis and instead favoring either cell growth arrest or proliferation.

The HN30 cells over-expressing NSP 5a3a showed by immunostaining an increase in cytoplasmic localization compared to controls while also being associated with likely apoptotic bodies. In contrast, the MCF-12a cells both treated and controls showed still mostly nuclear staining without any significant change in localization of NSP 5a3a when over-expressed (Fig. 3). Similarly, there was also an association of TRADD and TRAF2 with or nearby apoptotic bodies in HN30 cells over-expressing
NSP 5a3a (Fig. 5-6). While typically, apoptotic bodies and apoptotic blebs tend to be more associated with late stage apoptosis [134-135] being able to contain nuclear proteins, DNA, and RNA molecules [136] it would make sense that such proteins like: NSP 5a3a, TRADD and TRAF2, can exist and be included in such apoptotic bodies in such experimental conditions, which raises the question if these apoptotic bodies may be involved in extracellular induction of apoptosis with neighboring cells since it has been reported that apoptotic bodies can modulate intracellular communication [136-137]. Even though, mostly histone proteins 1-4 have been found inside apoptotic bodies as in the case of lymphoblasts [138], perhaps depending on the type of apoptotic induction and cell type, TNFR signaling proteins could remain encapsulated in these apoptotic bodies as in our case, and making it more intriguing is the fact that death receptor ligands, such as FasL and TRAIL have been found expressed on tumor microvesicles, albeit smaller than apoptotic bodies in size [139], in head and neck carcinoma from patients [140]. It opens possibilities if in the apoptotic scenario we present, that NSP 5a3a, TRAF2 and TRADD may be mediating apoptotic signals to other cells thru surface death receptor TNFR via apoptotic bodies or blebs that are formed. While, bleb formation has been also been found in early stages of apoptosis, being termed "marginal blebbing", which leads to more advanced stages of actual formation and separation of apoptotic bodies from dying cells, caspase activity was found associated with blebbing and apoptotic body formation, related to activation of at least either caspase 3 or 6 with also an increase in cytochrome c release from the mitochondria, this seen by TNFa induced apoptosis in Hela cells [141]. Though, again, we were not able to detect any caspase activity given the caspases we tested nor did we see any changes in cytochrome c levels as demonstrated in our previous study in HN30 treated cell [7].

We demonstrated in this subsequent study that NSP $5 \mathrm{a} 3 \mathrm{a}$ seems to be triggering apoptosis and mediating its effects through 2 distinct axis points in the TNFR-1 signaling pathway. One axis point involves p73 isoforms and DAXX while the other axis point involves TRAF2 with possibly TRADD. How NSP 5a3a may modulate any possible cross-talk between these signaling axis points, how these apoptotic adaptors interact with each other and with other signaling proteins, both in apoptotic and anti-apoptotic pathways depending on the cell type still warrants further investigation. It is known that scaffold proteins enable a high degree of specificity between interacting proteins and substrates as well being catalysts in signaling pathways such as the MAPK/JNK pathways [142-143], thereby being able to function as molecular assembly platforms, allowing various domains of proteins to interact in a flexible manner [143]. Besides being involved in regulating cellular communication at cellcell signaling junctions, coordinating assembly sequence 
interactions, scaffold proteins also have been found to participate in intracellular signaling in regulation of kinase cascade pathways, as well being themselves substrates for regulation in which a particular pathway may be switched on or off, and lastly being involved in regulatory feedback loops in a signaling pathway [143]. Interestingly, when we examined NSP 5a3a and compared its domain structure to recently identified scaffold proteins involved in MAPK/ JNK signaling, such as those proteins belonging to the JIP family, JIP1, JIP2, JIP3, and SPAG9 [144-145], we found an intriguing feature that NSP 5a3a shared with the JIP family proteins. Even though NSP 5a3a lacked particular domain features of the JIP family such as the JNK-binding domain, we did find potential MAPK/JNK docking sites known as the D-site in the NSP 5a3a amino acid sequence between amino acids: $361-515$. The D-site is characterized by the following consensus sequence: $(\mathrm{R} / \mathrm{K})_{3-5}(\mathrm{X})_{1-5}$ $(\Phi-\mathrm{X}-\Phi)$ where there is a group of basic residues followed by a spacer region and then a hydrophobic submotif [146]. In light of the expanding multiple roles and functions of structural scaffolding proteins in normal and pathologic physiological states, it would be of great interest in future studies to better understand how NSP 5a3a may regulate and be regulated itself involving these recently discovered axis points along the ASK1/JNK pathway and its possible molecular coordination of other signaling pathways that may cross-talk and converge with the ASK1/JNK pathway. Is it also of interest to investigate better how these axis points are coordinated between each other and how they may cross-talk, since it was recently reported that there is a cross-talk between p73 isoforms and c-JUN of the JNK pathway which can either lead to apoptosis or proliferation [147].

\section{MATERIALS AND METHODS}

\section{Cell Lines and Tissue Culture}

We used following cell lines in this study: HN30 (Head and Neck carcinoma) and MCF-12a (Normal Breast Epithelial). All these cell lines were obtained from ATCC and cultured at conditions recommended by ATCC except for the HN30 cell line which was a kind gift from Dr. George Yoo of the Department of Otolaryngology, Head and Neck Surgery, Wayne State University and Karmanos Cancer Institute, Detroit, Michigan.

\section{DNA Transfection and Western Blot Analysis}

Asynchronous HN30 and MCF-12a cells were seeded in 6 well-plates and transfected and optimized with Fugene HD (Roche) according to the manufacturer's protocol using 2 ug of plasmid DNA per well. Plasmids used for transfection were the following: pcDNA3.1/
CT-GFP (invitrogen) and pcDNA 3.0 NSP 5a3a. The NSP 5a3a cDNA had been cloned from a previous work [1]. The pcDNA3.1/CT-GFP vector was used to monitor transfection efficiency for all cell lines in the study.

HN30 and MCF-12a cells at three days posttransfection were harvested mechanically with a scraper, spun and washed twice with PBS $1 \mathrm{x}$ after which cells were prepped for western blot analysis. Cell pellets were lysed using a total lysis buffer $(50 \mathrm{mM}$ Tris- $\mathrm{Cl} \mathrm{pH} 7.4,5 \mathrm{mM}$ EDTA, $250 \mathrm{mM} \mathrm{NaCl}, 50 \mathrm{mM} \mathrm{NaF}, .1 \%$ Triton X-100, .1 $\mathrm{mM} \mathrm{Na} 3 \mathrm{VO} 4$, final volume with $\mathrm{dH} 2 \mathrm{O}$ ) for 15 minutes on ice then for 30 minutes on a rotator at 4 degrees. Lysates were spun down at 13,000 rpm for 15 minutes at 4 degrees after which supernatants were collected and protein concentration was determined by Bradford Assay. A total of $30 \mathrm{ug}$ of total protein was loaded for each sample and separated on $7 \%$ SDS-PAGE or $15 \%$ gel depending on the molecular weight of the proteins to be separated then followed by transfer onto Whatman Protran Nitrocellulose Transfer Membrane for 1.5 hours at 70 volts at 4 degrees.

Membranes were pre-blocked overnight at 4 degrees in 5\% milk buffer TTBS. Next day, membranes were cut and incubated with primary rabbit polyclonal NSP5a3a (Novus NB100-517A) at 1/500, primary rabbit polyclonal p73 ( Santa Cruz H-79) at 1/200, primary goat polyclonal p73 (Santa Cruz S-20) at 1/200, primary mouse monoclonal alpha-tubulin (Invitrogen) at 1/5000, primary rabbit polyclonal TRADD (Cell Signaling) $1 / 1000$, primary rabbit polyclonal TRAF2 (Novus NB10056173 ) at $1 / 1000$, primary rabbit polyclonal DAXX (Cell Signaling $25 \mathrm{C} 12$ ) at $1 / 1000$, primary rabbit polyclonal cleaved caspase 7 (Cell Signaling D198) at $1 / x$, primary rabbit polyclonal cleaved caspase 8 (Cell Signaling 18C8) at $1 / x$, rabbit primary polyclonal cleaved caspase 9 (Cell Signaling D3C5) at 1/x, primary rabbit polyclonal caspase 1 (Cell Signaling) at $1 / \mathrm{x}$ or primary mouse monoclonal B23 (Sigma) at 1/500 in 5\% milk buffer TTBS for 2 hours at RT.

Membranes were then washed 4 times at 15 minute intervals in $.1 \%$ Tween in PBS $1 \mathrm{x}$ then were incubated with secondary anti-rabbit HRP (Amersham Biosciences) at 1/5000, secondary anti-goat HRP (Amersham Biosciences) at $1 / 5000$ or secondary anti-mouse HRP (Amersham Biosciences) at 1/5000 in 5\% milk buffer for 1 hour at RT. Membranes were then again washed 4 times at 15 minute intervals each and then exposed for 3 minutes to ECL Chemiluminescent Detection Reagent (Perkin Elmer) to be developed on Kodak X-ray film.

\section{Co-immunoprecipitations and Western Blot Analysis}

Asynchronous HN30 cells were plated in $60 \mathrm{~mm}$ Dishes so they would be approximately $\sim 60 \%$ confluent next day for transfection. The day of transfection, HN30 
cells were transfected with recommended amount of pcDNA 3.0 NSP 5a3a and pcDNA 3.1/CT-GFP using Fugene HD (Roche) as indicated by the manufacturer. Three days after transfection, HN30 cells treated with pcDNA 3.0 NSP 5a3a and pcDNA 3.1/CT-GFP were harvested along with non-treated HN30 cells using a mechanical scraper. The cells were washed twice with PBS 1x after which Total lysis buffer was used to lyse cells. While cells were lysed, 100 ul of Protein A/G sepharose beads (Pierce) were washed with 900 ul cold lysis buffer, spun down for $\sim 30$ seconds at 11,000 rpm, then washed again with $1 \mathrm{ml}$ of cold lysis buffer, spun down and then were resuspended in $100 \mathrm{ul}$ of cold lysis buffer and kept at 4 degrees until needed. Approximately, 500-800 total protein for both treated and non-treated lysates were incubated with 25 ul of pre-washed protein A/G beads for 1 hour rotating at 4 degrees to pre-clear the lysates. After incubation with pre-washed beads, the lysates were spun down for 30 seconds at 11,000 rpm at 4 degrees, and then supernatants were transferred to prepped cold eppendorf tubes while the pre-cleared beads were saved at 4 degrees. The supernatants for both treated and non-treated were then split into equal amounts of total protein and were incubated with either $5 \mathrm{ug}$ of rabbit polyclonal NSP 5a3a (Novus), rabbit polyclonal DAXX (Cell Signaling), or rabbit polyclonal TRAF2 (Novus) for 1 hour rotating at 4 degrees. After supernatants incubated with their respective antibodies, approximately $25 \mathrm{ul}$ of pre-washed protein $\mathrm{A} / \mathrm{G}$ beads were added and allowed to incubate with the lysates plus antibodies rotating at 4 degrees overnight. The next day, the supernatants were spun down for 30 seconds at 11,000 rpm after which the supernatants were removed and the beads were washed 5 times with $500 \mathrm{ul}$ of cold total lysis buffer. Then, $25 \mathrm{ul}$ of Laemli 1x buffer with no beta-mercaptoethanol were added to the beads and not boiled after which the co-ips were loaded on a 7\% SDS-PAGE gel and the membranes were immunoblotted accordingly with rabbit polyclonal NSP 5a3a (Novus) at 1/500, rabbit polyclonal DAXX (Cell Signaling) at 1/1000, or rabbit polyclonal TRAF2 (Novus) at $1 / 1000$. Along with pre-cleared and pre-washed protein A/G beads, also primary rabbit IgGs was loaded on the gel as control.

\section{Immunofluorescence Staining}

Three days before immuno-staining, HN30 and MCF-12a cells were plated at a confluency of 150,000 cells per well of a 6 well plate and grown onto sterile coverslips $(22 \times 22 \times 1 \mathrm{~mm})$. The next day cells were either transfected with pcDNA 3.0 NSP 5a3a using Fugene HD (Roche) or left un-treated. Three days post-transfection, treated and non-treated cells were washed once with serum free medium for 2-3 minutes at room temperature and fixed in $4 \%$ paraformaldhyde for 20 minutes and permeabilized for 10 minutes at room temperature. Cells were pre-blocked for 1 hour at room temperature with $8 \%$ BSA in PBS 1x, then cells were incubated with either with rabbit polyclonal NSP 5a3a (Novus NB100-517A) at $1 / 500$, rabbit polyclonal TRADD (Cell Signaling) at 1/1000, rabbit polyclonal TRAF2 (Novus NB100-56173) at 1/1000, or rabbit polyclonal p73 (Santa Cruz H-79) at $1 / 200$ dilution in $1 \%$ BSA overnight at $4^{\circ} \mathrm{C}$. Next day, the primary antibody was removed and then after 3-5 washes in PBS 1 x for 3-5 minutes each wash, cells were incubated with anti-rabbit FITC (Invitrogen) at 1/700 dilution in $1 \%$ BSA in PBS $1 \mathrm{x}$ and incubated for 1 hour at room temperature. Cover slips were mounted on glass slides with vector shield plus DAPI and edges of cover slips sealed with nail hardener. Images were acquired on an Olympus IX81 Confocal microscope with a 60x oil objective. Single plane images were taken with a sensicam qe and acquired using the imaging software slidebook 4.1.0. Images were taken in one plane at a $.5 \mathrm{um}$ thickness.

\section{Light Microscopy}

Asynchronous HN30 and MCF-12a cells, three days post-transfection were observed for morphological changes using Zeiss Axiovert 25 microscope with 10x PH1 Zeiis objective.

\section{ACKNOWLEDGEMENTS}

This work was initiated in Dr. Giordano's laboratory in Temple University as part of the thesis research project of Luca D'Agostino supported by SHRO and NIH Grants to Dr. Antonio Giordano. I'd also like to thank again so kindly Novus Biologicals for their ongoing support in providing their indispensable anti-NSP 5a3a and antiTRAF2 antibodies which greatly helped our investigation and enabled a deeper understanding of the role of NSP $5 \mathrm{a} 3$ in apoptosis. We would like to thank the AICR (the Associazione Italiana Centro di Ricerca) for their support.

\section{REFERENCES}

1. Sang, N., Fath, D. M., Giordano, A. A gene highly expressed in tumor cells encodes novel structure proteins. Oncogene 2004; 23:9438-9446.

2. D'Agostino L, Giordano A. Possible functional role of NSPs in cancer. Cell Cycle. 2008; 7:1810-27.

3. Grisendi S, Mecucci C, Falini B, Pandolfi PP. Nucleophosmin and cancer. Nat Rev Cancer 2006; 6:493505.

4. D'Agostino L, Caracciolo V, Giordano A. NSP 5a3a's link to nuclear-cyto proteins B23 and hnRNP-L between normal and aberrant breast cell lines. Cell Cycle. 2010; 9:6.

5. Huang S. perinucleolar structures. J Struct Biol. 2000 129:233-40. 
6. Hung LH, Heiner M, Hui J, Schreiner S, Benes V, Bindereif A. Diverse roles of hnRNP L in mammalian mRNA processing: a combined microarray and RNAi analysis. RNA. 2008 14:284-96.

7. D'agostino L, Giordano A. NSP 5a3a: a potential novel cancer target in head and neck carcinoma. Oncotarget. 2010 1:423-35.

8. Wong DT, Todd R, Tsuji T, Donoff RB. Molecular biology of human oral cancer. Crit Rev Oral Biol Med. 1996; 7:31928.

9. Biolchini F, Pollastri G, Figurelli S, Chiarini L. Carcinogen metabolism, DNA damage repair and oral head and neck squamocellular carcinoma (HNSCC). Minerva Stomatol. 2005; 54:405-14.

10. Ferris RL. Progress in head and neck cancer immunotherapy: can tolerance and immune suppression be reversed? ORL J Otorhinolaryngol Relat Spec. 2004; 66:332-40.

11. Lin CJ, Grandis JR, Carey TE, Gollin SM, Whiteside TL, Koch WM, Ferris RL, Lai SY. Head and neck squamous cell carcinoma cell lines: established models and rationale for selection. Head Neck. 2007; 29:163-88.

12. Chiou SH, Yu CC, Huang CY, Lin SC, Liu CJ, Tsai TH, Chou SH, Chien CS, Ku HH, Lo JF. Positive correlations of Oct-4 and Nanog in oral cancer stem-like cells and highgrade oral squamous cell carcinoma. Clin Cancer Res. 2008; 14:4085-95.

13. Kornfeld JW, Meder S, Wohlberg M, Friedrich RE, Rau T, Riethdorf L, Löning T, Pantel K, Riethdorf S. Overexpression of TACE and TIMP3 mRNA in head and neck cancer: association with tumour development and progression. Br J Cancer. 2011; 104:138-45.

14. Bergmann C, Strauss L, Wang Y, Szczepanski MJ, Lang S, Johnson JT, Whiteside TL. T regulatory Type 1 cells in squamous cell carcinoma of the head and neck: mechanisms of suppression and expansion in advanced disease. Clin Cancer Res. 2008; 14:3706-15.

15. Gold KA, Kim ES. Role of molecular markers and gene profiling in head and neck cancers. Curr Opin Oncol. 2009; 21:206-11.

16. Culliney B, Birhan A, Young AV, Choi W, Shulimovich M, Blum RH. Management of locally advanced or unresectable head and neck cancer. Oncology. 2008; 22:1152-61.

17. Liebertz DJ, Lechner MG, Masood R, Sinha UK, Han J, Puri RK, Correa AJ, Epstein AL. Establishment and characterization of a novel head and neck squamous cell carcinoma cell line USC-HN1. Head Neck Oncol. 2010; 2:5.

18. Holmes JD, Martin RA, Gutta R. Characteristics of head and neck cancer patients referred to an oral and maxillofacial surgeon in the United States for management. J Oral Maxillofac Surg. 2010; 68:555-61.

19. Mayne ST, Cartmel B, Kirsh V, Goodwin WJ Jr. Alcohol and tobacco use prediagnosis and postdiagnosis, and survival in a cohort of patients with early stage cancers of the oral cavity, pharynx, and larynx. Cancer Epidemiol Biomarkers Prev. 2009; 18:3368-74.

20. Schlecht NF, Burk RD, Adrien L, Dunne A, Kawachi N, Sarta C, Chen Q, Brandwein-Gensler M, Prystowsky MB, Childs G, Smith RV, Belbin TJ. Gene expression profiles in HPV-infected head and neck cancer. J Pathol. 2007; 213:283-93.

21. Yoo GH, Washington J, Oliver J, Piechocki M, Kim H, Foster-Nora J, Shibuya TY, Wilson DR, Ensley JF. The effects of exogenous p53 overexpression on HPV-immortalized and carcinogen transformed oral keratinocytes. Cancer. 2002; 94:159-66.

22. ElOjeimy S, McKillop JC, El-Zawahry AM, Holman DH, Liu X, Schwartz DA, Day TA, Dong JY, Norris JS. FasL gene therapy: a new therapeutic modality for head and neck cancer. Cancer Gene Ther. 2006; 13:739-45.

23. Kerr JF, Wyllie AH, Currie AR. Apoptosis: a basic biological phenomenon with wide-ranging implications in tissue kinetics. Br J Cancer. 1972; 26:239-57.

24. Rinkenberger JL, Korsmeyer SJ. Errors of homeostasis and deregulated apoptosis. Curr Opin Genet Dev. 1997; 7:58996.

25. Jacobson MD, Weil M, Raff MC. Programmed cell death in animal development. Cell. 1997; 88:347-54.

26. Thompson CB. Apoptosis in the pathogenesis and treatment of disease. Science. 1995; 267:1456-62.

27. Hellwig CT, Passante E, Rehm M. The molecular machinery regulating apoptosis signal transduction and its implication in human physiology and pathophysiologies. Curr Mol Med. 2011; 11:31-47.

28. Tischner D, Woess C, Ottina E, Villunger A. Bcl-2regulated cell death signalling in the prevention of autoimmunity. Cell Death Dis. 2010; 1:e48.

29. Culmsee C, Landshamer S. Molecular insights into mechanisms of the cell death program: role in the progression of neurodegenerative disorders. Curr Alzheimer Res. 2006; 3:269-83.

30. Saraste A, Pulkki K. Morphologic and biochemical hallmarks of apoptosis. Cardiovasc Res. 2000; 45:528-37.

31. Sanfilippo CM, Blaho JA. The facts of death. Int Rev Immunol. 2003; 22:327-40.

32. Saraste A. Morphologic criteria and detection of apoptosis. Herz. 1999; 24:189-95.

33. Lavrik IN. Systems biology of apoptosis signaling networks. Curr Opin Biotechnol. 2010; 21:551-5.

34. Jin Z, El-Deiry WS. Distinct signaling pathways in TRAILversus tumor necrosis factor-induced apoptosis. Mol Cell Biol. 2006; 26:8136-48.

35. Thorburn A. Death receptor-induced cell killing. Cell Signal. 2004; 16:139-44.

36. Naudé PJ, den Boer JA, Luiten PG, Eisel UL. Tumor necrosis factor receptor cross-talk. FEBS J. 2011; 278:88898. 
37. Micheau O, Tschopp J. Induction of TNF receptor I-mediated apoptosis via two sequential signaling complexes. Cell. 2003; 114:181-90.

38. Thome M, Hofmann K, Burns K, Martinon F, Bodmer JL, Mattmann C, Tschopp J. Identification of CARDIAK, a RIP-like kinase that associates with caspase-1. Curr Biol. 1998; 8:885-8.

39. Twiddy D, Brown DG, Adrain C, Jukes R, Martin SJ, Cohen GM, MacFarlane M, Cain K. Pro-apoptotic proteins released from the mitochondria regulate the protein composition and caspase-processing activity of the native Apaf-1/caspase-9 apoptosome complex. J Biol Chem. 2004; 279:19665-82.

40. Caroppi P, Sinibaldi F, Fiorucci L, Santucci R. Apoptosis and human diseases: mitochondrion damage and lethal role of released cytochrome $\mathrm{C}$ as proapoptotic protein. Curr Med Chem. 2009; 16:4058-65.

41. Fulda S, Debatin KM. Extrinsic versus intrinsic apoptosis pathways in anticancer chemotherapy. Oncogene. 2006; 25:4798-811.

42. Parsons MJ, Green DR. Mitochondria in cell death. Essays Biochem. 2010; 47:99-114.

43. Duckett CS. IAP proteins: sticking it to Smac. Biochem J. $2005 ; 385: \mathrm{e} 1-2$

44. Harada H, Grant S. Apoptosis regulators. Rev Clin Exp Hematol. 2003; 7:117-38.

45. Bredesen DE. Apoptosis: overview and signal transduction pathways. J Neurotrauma. 2000; 17:801-10.

46. Cullen SP, Martin SJ. Caspase activation pathways: some recent progress. Cell Death Differ. 2009; 16:935-8.

47. Chung JY, Park YC, Ye H, Wu H. All TRAFs are not created equal: common and distinct molecular mechanisms of TRAF-mediated signal transduction. J Cell Sci. 2002; 115:679-88.

48. Baeuerle PA, Baltimore D. NF-kappa B: ten years after. Cell. 1996 Oct 4; 87:13-20.

49. Beg AA, Baltimore D. An essential role for NF-kappaB in preventing TNF-alpha-induced cell death. Science. 1996; 274:782-4.

50. Shaulian E, Karin M. AP-1 in cell proliferation and survival. Oncogene. 2001; 20:2390-400.

51. Kaltschmidt B, Kaltschmidt C, Hofmann TG, Hehner SP, Dröge W, Schmitz ML. The pro- or anti-apoptotic function of NF-kappaB is determined by the nature of the apoptotic stimulus. Eur J Biochem. 2000; 267:3828-35.

52. Karin M, Shaulian E. AP-1: linking hydrogen peroxide and oxidative stress to the control of cell proliferation and death. IUBMB Life. 2001; 52:17-24.

53. Chen G, Goeddel DV. TNF-R1 signaling: a beautiful pathway. Science. 2002; 296:1634-5.

54. Au PY, Yeh WC. Physiological roles and mechanisms of signaling by TRAF2 and TRAF5. Adv Exp Med Biol. 2007; 597:32-47.
55. Manna SK, Babajan B, Raghavendra PB, Raviprakash N, Sureshkumar C. Inhibiting TRAF2-mediated activation of NF-kappaB facilitates induction of AP-1. J Biol Chem. 2010; 285:11617-27.

56. Zhang H, Zhang R, Luo Y, D'Alessio A, Pober JS, Min W. AIP1/DAB2IP, a novel member of the Ras-GAP family, transduces TRAF2-induced ASK1-JNK activation. J Biol Chem. 2004; 279:44955-65.

57. Bradley JR, Pober JS. Tumor necrosis factor receptorassociated factors (TRAFs). Oncogene. 2001; 20:6482-91.

58. Bisso A, Collavin L, Del Sal G. p73 as a pharmaceutical target for cancer therapy. Curr Pharm Des. 2011; 17:57890.

59. Danilova N, Sakamoto KM, Lin S. p53 family in development. Mech Dev. 2008; 125:919-31.

60. Moll UM, Slade N. p63 and p73: roles in development and tumor formation. Mol Cancer Res. 2004; 2:371-86.

61. Talos F, Abraham A, Vaseva AV, Holembowski L, Tsirka SE, Scheel A, Bode D, Dobbelstein M, Brück W, Moll UM. p73 is an essential regulator of neural stem cell maintenance in embryonal and adult CNS neurogenesis. Cell Death Differ. 2010; 17:1816-29.

62. Yang A, Kaghad M, Caput D, McKeon F. On the shoulders of giants: p63, p73 and the rise of p53. Trends Genet. 2002; 18:90-5.

63. Nakagawa T, Takahashi M, Ozaki T, Watanabe K, Hayashi S, Hosoda M, Todo S, Nakagawara A. Negative autoregulation of $\mathrm{p} 73$ and $\mathrm{p} 53$ by DeltaNp73 in regulating differentiation and survival of human neuroblastoma cells. Cancer Lett. 2003; 197:105-9.

64. Moll UM, Slade N. p63 and p73: roles in development and tumor formation. Mol Cancer Res. 2004; 2:371-86.

65. Ozaki T, Nakagawara A. p73, a sophisticated p53 family member in the cancer world. Cancer Sci. 2005; 96:729-37.

66. Tozluoğlu M, Karaca E, Haliloglu T, Nussinov R. Cataloging and organizing p73 interactions in cell cycle arrest and apoptosis. Nucleic Acids Res. 2008; 36:5033-49.

67. Nakagawa T, Takahashi M, Ozaki T, Watanabe Ki K, Todo S, Mizuguchi H, Hayakawa T, Nakagawara A. Autoinhibitory regulation of $\mathrm{p} 73$ by Delta Np73 to modulate cell survival and death through a p73-specific target element within the Delta Np73 promoter. Mol Cell Biol. 2002; 22:2575-85.

68. Ramadan S, Terrinoni A, Catani MV, Sayan AE, Knight RA, Mueller M, Krammer PH, Melino G, Candi E. p73 induces apoptosis by different mechanisms. Biochem Biophys Res Commun. 2005; 331:713-7.

69. Terrasson J, Allart S, Martin H, Lulé J, Haddada H, Caput D, Davrinche C. p73-dependent apoptosis through death receptor: impairment by human cytomegalovirus infection. Cancer Res. 2005; 65:2787-94.

70. Dhanasekaran DN, Reddy EP. JNK signaling in apoptosis. Oncogene. 2008; 27:6245-51.

71. Jones EV, Dickman MJ, Whitmarsh AJ. Regulation of p73- 
mediated apoptosis by c-Jun N-terminal kinase. Biochem J. 2007; 405:617-23.

72. Kim EJ, Park JS, Um SJ. Identification of Daxx interacting with $\mathrm{p} 73$, one of the $\mathrm{p} 53$ family, and its regulation of $\mathrm{p} 53$ activity by competitive interaction with PML. Nucleic Acids Res. 2003; 31:5356-67.

73. Byers TJ, Husain-Chishti A, Dubreuil RR, Branton D, Goldstein LS. Sequence similarity of the amino-terminal domain of Drosophila beta spectrin to alpha actinin and dystrophin. J Cell Biol. 1989; 109:1633-41.

74. Davison MD, Baron MD, Critchley DR, Wootton JC. Structural analysis of homologous repeated domains in alpha-actinin and spectrin. Int J Biol Macromol. 1989; 11:81-90.

75. De Matteis MA, Morrow JS. Spectrin tethers and mesh in the biosynthetic pathway. J Cell Sci. 2000; 113:2331-43.

76. Phillips MD, Thomas GH. Brush border spectrin is required for early endosome recycling in Drosophila. J Cell Sci. 2006; 119:1361-70.

77. Yang CH, Lambie EJ, Snyder M. NuMA: an unusually long coiled-coil related protein in the mammalian nucleus. J Cell Biol. 1992; 116:1303-17.

78. Machesky LM, Johnston SA. MIM: a multifunctional scaffold protein. J Mol Med. 2007; 85:569-76.

79. Reed JC. Drug insight: cancer therapy strategies based on restoration of endogenous cell death mechanisms. Nat Clin Pract Oncol. 2006; 3:388-98.

80. Fischer U, Schulze-Osthoff K. Apoptosis-based therapies and drug targets. Cell Death Differ. 2005; 12 Suppl 1:94261 .

81. dos Santos LV, Carvalho AL. Bcl-2 targeted-therapy for the treatment of head and neck squamous cell carcinoma. Recent Pat Anticancer Drug Discov. 2011; 6:45-57.

82. Fukazawa T, Matsuoka J, Yamatsuji T, Maeda Y, Durbin ML, Naomoto Y. Adenovirus-mediated cancer gene therapy and virotherapy (Review). Int J Mol Med. 2010; 25:3-10.

83. Murray-Zmijewski F, Lane DP, Bourdon JC. p53/p63/ p73 isoforms: an orchestra of isoforms to harmonise cell differentiation and response to stress. Cell Death Differ. 2006; 13:962-72

84. Dulloo I, Sabapathy K. Transactivation-dependent and -independent regulation of p73 stability. J Biol Chem. 2005; 280:28203-14.

85. Cabrera-Socorro A, Pueyo Morlans M, Suarez Sola ML, Gonzalez Delgado FJ, Castañeyra-Perdomo A, Marin MC, Meyer G. Multiple isoforms of the tumor protein p73 are expressed in the adult human telencephalon and choroid plexus and present in the cerebrospinal fluid. Eur J Neurosci. 2006; 23:2109-18.

86. Watson IR, Irwin MS. Ubiquitin and ubiquitin-like modifications of the p53 family. Neoplasia. 2006; 8:65566. Review.

87. Oberst A, Rossi M, Salomoni P, Pandolfi PP, Oren M,
Melino G, Bernassola F. Regulation of the p73 protein stability and degradation. Biochem Biophys Res Commun. 2005; 331:707-12.

88. Castellino RC, De Bortoli M, Lin LL, Skapura DG, Rajan JA, Adesina AM, Perlaky L, Irwin MS, Kim JY. Overexpressed TP73 induces apoptosis in medulloblastoma. BMC Cancer. 2007; 7:127.

89. Minty A, Dumont X, Kaghad M, Caput D. Covalent modification of p73alpha by SUMO-1. Two-hybrid screening with p73 identifies novel SUMO-1-interacting proteins and a SUMO-1 interaction motif. J Biol Chem. 2000; 275:36316-23.

90. Stehmeier P, Muller S. Regulation of p53 family members by the ubiquitin-like SUMO system. DNA Repair (Amst). 2009; 8:491-8.

91. Salomoni P, Khelifi AF. Daxx: death or survival protein? Trends Cell Biol. 2006; 16:97-104.

92. Lin DY, Huang YS, Jeng JC, Kuo HY, Chang CC, Chao TT, Ho CC, Chen YC, Lin TP, Fang HI, Hung CC, Suen CS, Hwang MJ, Chang KS, Maul GG, Shih HM. Role of SUMO-interacting motif in Daxx SUMO modification, subnuclear localization, and repression of sumoylated transcription factors. Mol Cell. 2006; 24:341-54.

93. Gostissa M, Morelli M, Mantovani F, Guida E, Piazza S, Collavin L, Brancolini C, Schneider C, Del Sal G. The transcriptional repressor hDaxx potentiates p53-dependent apoptosis. J Biol Chem. 2004; 279:48013-23.

94. Puto LA, Reed JC. Daxx represses RelB target promoters via DNA methyltransferase recruitment and DNA hypermethylation. Genes Dev. 2008; 22:998-1010.

95. Chen LY, Chen JD. Daxx silencing sensitizes cells to multiple apoptotic pathways. Mol Cell Biol. 2003; 23:710821.

96. Chang HY, Nishitoh H, Yang X, Ichijo H, Baltimore D. Activation of apoptosis signal-regulating kinase 1 (ASK1) by the adapter protein Daxx. Science. 1998; 281:1860-3.

97. Charette SJ, Lavoie JN, Lambert H, Landry J. Inhibition of Daxx-mediated apoptosis by heat shock protein 27. Mol Cell Biol. 2000; 20:7602-12.

98. Charette SJ, Lambert H, Landry J. A kinase-independent function of Ask1 in caspase-independent cell death. J Biol Chem. 2001; 276:36071-4.

99. Ko YG, Kang YS, Park H, Seol W, Kim J, Kim T, Park HS, Choi EJ, Kim S. Apoptosis signal-regulating kinase 1 controls the proapoptotic function of death-associated protein (Daxx) in the cytoplasm. J Biol Chem. 2001; 276:39103-6.

100. Kim EJ, Park JS, Um SJ. Identification of Daxx interacting with $\mathrm{p} 73$, one of the $\mathrm{p} 53$ family, and its regulation of $\mathrm{p} 53$ activity by competitive interaction with PML. Nucleic Acids Res. 2003; 31:5356-67.

101. Hollenbach AD, McPherson CJ, Mientjes EJ, Iyengar R, Grosveld G. Daxx and histone deacetylase II associate with chromatin through an interaction with core histones 
and the chromatin-associated protein Dek. J Cell Sci. 2002; 115:3319-30.

102. Domínguez G, García JM, Peña C, Silva J, García V, Martínez L, Maximiano C, Gómez ME, Rivera JA, GarcíaAndrade C, Bonilla F. DeltaTAp73 upregulation correlates with poor prognosis in human tumors: putative in vivo network involving p73 isoforms, p53, and E2F-1. J Clin Oncol. 2006; 24:805-15.

103. Di Vinci A, Sessa F, Casciano I, Banelli B, Franzi F, Brigati C, Allemanni G, Russo P, Dominioni L, Romani M. Different intracellular compartmentalization of TA and DeltaNp73 in non-small cell lung cancer. Int J Oncol. 2009; 34:449-56.

104. Nekulová M, Zitterbart K, Sterba J, Veselská R. Analysis of the intracellular localization of p73 N-terminal protein isoforms TAp73 and $\Delta \mathrm{Np} 73$ in medulloblastoma cell lines. J Mol Histol. 2010; 41:267-75.

105. Bernassola F, Salomoni P, Oberst A, Di Como CJ, Pagano M, Melino G, Pandolfi PP. Ubiquitin-dependent degradation of p73 is inhibited by PML. J Exp Med. 2004; 199:1545-57.

106. Dobbelstein M, Strano S, Roth J, Blandino G. p73-induced apoptosis: a question of compartments and cooperation. Biochem Biophys Res Commun. 2005; 331:688-93.

107. Soldani C, Scovassi AI. Poly (ADP-ribose) polymerase-1 cleavage during apoptosis: an update. Apoptosis. 2002; 7:321-8.

108. Nielsen CH, Albertsen L, Bendtzen K, Baslund B. Methotrexate induces poly (ADP-ribose) polymerasedependent, caspase 3-independent apoptosis in subsets of proliferating CD4+ T cells. Clin Exp Immunol. 2007; 148:288-95.

109. Kondo K, Obitsu S, Ohta S, Matsunami K, Otsuka H, Teshima R. Poly(ADP-ribose) polymerase (PARP)-1independent apoptosis-inducing factor (AIF) release and cell death are induced by eleostearic acid and blocked by alpha-tocopherol and MEK inhibition. J Biol Chem. 2010; 285:13079-91.

110. Chang HY, Nishitoh H, Yang X, Ichijo H, Baltimore D. Activation of apoptosis signal-regulating kinase 1 (ASK1) by the adapter protein Daxx. Science. 1998; 281:1860-3.

111. Yang Y, Zhao S, Song J. Caspase-dependent apoptosis and -independent poly (ADP-ribose) polymerase cleavage induced by transforming growth factor beta 1 . Int J Biochem Cell Biol. 2004; 36:223-34.

112. Boehrer S, Nowak D, Hochmuth S, Kim SZ, Trepohl B, Afkir A, Hoelzer D, Mitrou PS, Weidmann E, Chow KU. Daxx overexpression in T-lymphoblastic Jurkat cells enhances caspase-dependent death receptor- and druginduced apoptosis in distinct ways. Cell Signal. 2005; 17:581-95.

113. MacFarlane M, Cohen GM, Dickens M. JNK (c-Jun $\mathrm{N}$-terminal kinase) and p38 activation in receptor-mediated and chemically-induced apoptosis of T-cells: differential requirements for caspase activation. Biochem J. 2000; 348:93-101.

114. Doonan F, Donovan M, Cotter TG. Caspase-independent photoreceptor apoptosis in mouse models of retinal degeneration. J Neurosci. 2003; 23:5723-31.

115. Yang Y, Zhao S, Song J. Caspase-dependent apoptosis and -independent poly (ADP-ribose) polymerase cleavage induced by transforming growth factor beta1. Int J Biochem Cell Biol. 2004; 36:223-34.

116. Park YC, Burkitt V, Villa AR, Tong L, Wu H. Structural basis for self-association and receptor recognition of human TRAF2. Nature. 1999; 398:533-8.

117. Zhang L, Blackwell K, Shi Z, Habelhah H. The RING domain of TRAF2 plays an essential role in the inhibition of TNFalpha-induced cell death but not in the activation of NF-kappaB. J Mol Biol. 2010; 396:528-39.

118. Reinhard C, Shamoon B, Shyamala V, Williams LT. Tumor necrosis factor alpha-induced activation of c-jun $\mathrm{N}$-terminal kinase is mediated by TRAF2. EMBO J. 1997; 16:1080-92.

119. Habelhah H, Takahashi S, Cho SG, Kadoya T, Watanabe $\mathrm{T}$, Ronai Z. Ubiquitination and translocation of TRAF2 is required for activation of JNK but not of p38 or NFkappaB. EMBO J. 2004; 23:322-32.

120. Martinez-Forero I, Rouzaut A, Palazon A, Dubrot J, Melero I. Lysine 63 polyubiquitination in immunotherapy and in cancer-promoting inflammation. Clin Cancer Res. 2009; 15:6751-7.

121. Min W, Bradley JR, Galbraith JJ, Jones SJ, Ledgerwood EC, Pober JS. The N-terminal domains target TNF receptorassociated factor-2 to the nucleus and display transcriptional regulatory activity. J Immunol. 1998; 161:319-24.

122. Martin AG. NFאB anti-apoptotic or pro-apoptotic, maybe both. Cell Cycle. 2010; 9:3131-2

123. Kaltschmidt B, Heinrich M, Kaltschmidt C. Stimulusdependent activation of NF-kappaB specifies apoptosis or neuroprotection in cerebellar granule cells. Neuromolecular Med. 2002; 2:299-309.

124. Hu P, Han Z, Couvillon AD, Kaufman RJ, Exton JH. Autocrine tumor necrosis factor alpha links endoplasmic reticulum stress to the membrane death receptor pathway through IRE1alpha-mediated NF-kappaB activation and down-regulation of TRAF2 expression. Mol Cell Biol. 2006; 26:3071-84.

125. Nishitoh H, Saitoh M, Mochida Y, Takeda K, Nakano H, Rothe M, Miyazono K, Ichijo H. ASK1 is essential for JNK/SAPK activation by TRAF2. Mol Cell. 1998; 2:38995.

126. Yuasa T, Ohno S, Kehrl JH, Kyriakis JM. Tumor necrosis factor signaling to stress-activated protein kinase (SAPK)/ Jun NH2-terminal kinase (JNK) and p38. Germinal center kinase couples TRAF2 to mitogen-activated protein kinase/ ERK kinase kinase 1 and SAPK while receptor interacting protein associates with a mitogen-activated protein kinase 
kinase kinase upstream of MKK6 and p38. J Biol Chem. 1998; 273:22681-92.

127. Hsu H, Shu HB, Pan MG, Goeddel DV. TRADD-TRAF2 and TRADD-FADD interactions define two distinct TNF receptor 1 signal transduction pathways. Cell. 1996; 84:299-308.

128. Pobezinskaya YL, Kim YS, Choksi S, Morgan MJ, Li T, Liu C, Liu Z. The function of TRADD in signaling through tumor necrosis factor receptor 1 and TRIF-dependent Tolllike receptors. Nat Immunol. 2008; 9:1047-54.

129. Bender LM, Morgan MJ, Thomas LR, Liu ZG, Thorburn A. The adaptor protein TRADD activates distinct mechanisms of apoptosis from the nucleus and the cytoplasm. Cell Death Differ. 2005; 12:473-81.

130. Jackson-Bernitsas DG, Ichikawa H, Takada Y, Myers JN, Lin XL, Darnay BG, Chaturvedi MM, Aggarwal BB. Evidence that TNF-TNFR1-TRADD-TRAF2-RIP-TAK1IKK pathway mediates constitutive NF-kappaB activation and proliferation in human head and neck squamous cell carcinoma. Oncogene. 2007; 26:1385-97.

131. Nguyen LT, Duncan GS, Mirtsos C, Ng M, Speiser DE, Shahinian A, Marino MW, Mak TW, Ohashi PS, Yeh WC. TRAF2 deficiency results in hyperactivity of certain TNFR1 signals and impairment of CD40-mediated responses. Immunity. 1999; 11:379-89.

132. Itahana K, Bhat KP, Jin A, Itahana Y, Hawke D, Kobayashi R, Zhang Y. Tumor suppressor ARF degrades B23, a nucleolar protein involved in ribosome biogenesis and cell proliferation. Mol Cell. 2003; 12:1151-64.

133. Lindström MS, Zhang Y. Ribosomal protein S9 is a novel B23/NPM-binding protein required for normal cell proliferation. J Biol Chem. 2008; 283:15568-76.

134. Prieto A, Díaz D, Barcenilla H, García-Suárez J, Reyes E, Monserrat J, San Antonio E, Melero D, de la Hera A, Orfao A, Alvarez-Mon M. Apoptotic rate: a new indicator for the quantification of the incidence of apoptosis in cell cultures. Cytometry. 2002; 48:185-93.

135. Lane JD, Allan VJ, Woodman PG. Active relocation of chromatin and endoplasmic reticulum into blebs in late apoptotic cells. J Cell Sci. 2005; 118:4059-71.

136. Mathivanan S, Ji H, Simpson RJ. Exosomes: extracellular organelles important in intercellular communication. J Proteomics. 2010; 73:1907-20.

137. Taylor DD, Gercel-Taylor C. Exosomes/microvesicles: mediators of cancer-associated immunosuppressive microenvironments. Semin Immunopathol. 2011 Jun 19. Abstract.

138. Schiller M, Bekeredjian-Ding I, Heyder P, Blank N, Ho AD, Lorenz HM. Autoantigens are translocated into small apoptotic bodies during early stages of apoptosis. Cell Death Differ. 2008; 15:183-91.

139. Martínez-Lorenzo MJ, Anel A, Gamen S, Monle n I, Lasierra P, Larrad L, Piñeiro A, Alava MA, Naval J. Activated human $\mathrm{T}$ cells release bioactive Fas ligand and
APO2 ligand in microvesicles. J Immunol. 1999; 163:127481.

140. Bergmann C, Strauss L, Wieckowski E, Czystowska M, Albers A, Wang Y, Zeidler R, Lang S, Whiteside TL. Tumor-derived microvesicles in sera of patients with head and neck cancer and their role in tumor progression. Head Neck. 2009; 31:371-80.

141. Domnina LV, Ivanova OY, Pletjushkina OY, Fetisova EK, Chernyak BV, Skulachev VP, Vasiliev JM. Marginal blebbing during the early stages of TNF-induced apoptosis indicates alteration in actomyosin contractility. Cell Biol Int. 2004; 28:471-5.

142. Engström W, Ward A, Moorwood K. The role of scaffold proteins in JNK signalling. Cell Prolif. 2010; 43:56-66.

143. Good MC, Zalatan JG, Lim WA. Scaffold proteins: hubs for controlling the flow of cellular information. Science. 2011; 332:680-6.

144. Jagadish N, Rana R, Selvi R, Mishra D, Garg M, Yadav S, Herr JC, Okumura K, Hasegawa A, Koyama K, Suri A. Characterization of a novel human sperm-associated antigen 9 (SPAG9) having structural homology with c-Jun $\mathrm{N}$-terminal kinase-interacting protein. Biochem J. 2005; 389:73-82.

145. Garg M, Kanojia D, Suri S, Gupta S, Gupta A, Suri A. Sperm-associated antigen 9: a novel diagnostic marker for thyroid cancer. J Clin Endocrinol Metab. 2009; 94:4613-8.

146. Whisenant TC, Ho DT, Benz RW, Rogers JS, Kaake RM, Gordon EA, Huang L, Baldi P, Bardwell L. Computational prediction and experimental verification of new MAP kinase docking sites and substrates including Gli transcription factors. PLoS Comput Biol. 2010; 6. pii: e1000908.

147. Koeppel M, van Heeringen SJ, Kramer D, Smeenk L, Janssen-Megens E, Hartmann M, Stunnenberg HG, Lohrum M. Crosstalk between c-Jun and TAp73 \{alpha\}/ \{beta\} contributes to the apoptosis-survival balance. Nucleic Acids Res. 2011 Mar 31. [Epub ahead of print] 